Cognitive ability, life-long learning and social mobility in Britain: Do further qualifications provide second chances for bright people from disadvantaged backgrounds?

\author{
Erzsébet Bukodi \\ Department of Social Policy and Intervention and \\ Nuffield College \\ University of Oxford \\ Mollie Bourne \\ Department of Social Policy and Intervention and \\ Nuffield College \\ University of Oxford \\ Bastian Betthäuser \\ Department of Social Policy and Intervention and \\ University of Oxford
}

Accepted for publication in European Sociological Review 


\title{
Cognitive ability, life-long learning and social mobility in Britain: Do further qualifications provide second chances for bright people from disadvantaged backgrounds?
}

\begin{abstract}
There is evidence to show that, even among individuals who have relatively high levels of cognitive ability, coming from disadvantaged social origins hinders their chances of securing high levels of qualification and advantaged labour market positions. But it has been argued that lifelong learning could provide second chances for these people through providing an alternative route to high qualifications. The main objective of this paper is to examine this issue. We pose two questions. Does further education enable individuals from disadvantaged origins but with a high level of cognitive ability to improve on their initial levels of qualification? And does any such improvement then lead to better labour market positions, in terms of social class, for these individuals? Based on the complete qualifications histories of individuals in the 1970 British Birth Cohort Study, our analyses show that men and women from disadvantaged origins, especially if of high ability, are indeed able to raise their levels of qualification; but they do so mainly via the attainment of further vocational, rather than further academic, qualifications. And while our results also indicate that acquiring further academic qualifications does improve the upward mobility chances of people of high ability from disadvantaged backgrounds, a similar effect does not show up from acquiring further vocational qualifications. In addition, we find that there remains a substantial 'direct effect' of cognitive ability on class attainment. This suggests that obtaining further academic qualifications is only one channel for upward mobility, and that there are others which are more directly related to ability.
\end{abstract}




\section{Introduction}

Existing evidence suggests that, even with individuals of high cognitive ability, coming from disadvantaged parental backgrounds hinders their chances of attaining a high level of qualification and, in turn, constrains their ability to reach advantaged labour market positions in later life (Authors). But in many societies over recent decades there has been a substantial growth in opportunities for further education and for 'lifelong learning' more generally (Riddell and Markowitsch, 2012; Bablavy et al., 2014). This development, it has then been thought, could reduce the barriers to educational attainment for individuals coming from less advantaged backgrounds, especially if they are bright. In Britain, overall participation rates in further education is around $15 \%$ among the 25 -to-64-years-olds - one of the highest rates in Europe (Jenkins, 2013; Desjardins, 2015). And policy rhetoric has emphasised the potential benefits of further education, not only for up-skilling the workforce and promoting national economic competitiveness, but also in offering 'second chances' for those who failed to achieve a good level of education before entering the labour market and in this way preventing a 'wastage of talent' (Appleby and Bathmaker, 2006; Jenkins, 2017). In this paper, we aim to examine the extent to which lifelong learning does in fact promote upward social mobility, with a focus on individuals with high levels of cognitive ability but who come from disadvantaged social origins. More specifically, we pose the two following research questions. (1) Does further education enable individuals with high cognitive ability but from disadvantaged backgrounds to improve on their initial levels of qualification? (2) Does any such improvement in qualifications lead to the attainment of better labour market positions, in terms of social class, for the individuals in question? We focus on social class returns to further education because 
class more fully captures the intergenerational transmission of economic advantage and disadvantage than is the case for individuals' earnings (Erikson and Goldthorpe, 2010).

Past research shows that the propensity for pursuing further education varies with such individual characteristics as age (e.g., Dämmrich et al., 2014), initial level of education (e.g., Jenkins et al., 2003) and employment status (e.g., Blanden et al., 2012). The returns to further education, in terms of earnings, occupational status or class position, have also been explored, although with often inconsistent if not conflicting findings (e.g., Jenkins et al., 2003; Blanden et al., 2012; Dorsett et al., 2011; Blossfeld et al., 2014). This could well be the result of significant limitations in research so far carried out in this area. Rather little is in fact known about the relation between social origins and life-long learning, and still less about the part that is played by individuals' cognitive ability in their participation and in their success in lifelong learning. Further, past research has not consistently distinguished between life-long learning leading to academic as opposed to vocational qualifications. This is a serious shortcoming, and certainly so far as the British case is concerned. Not only do academic qualifications tend to be regarded as the more prestigious but they also lead to generally higher labour market returns than do vocational qualifications in that the latter are often restricted to increasing skills of a highly occupation- or sector-specific kind (Wolf et al., 2006; Wolf, 2011).

This paper seeks to advance our understanding of the role of lifelong learning in the intergenerational transmission of economic (dis-)advantage by conducting analyses in which individuals' social origins and cognitive ability are included together, and in which both the chances of acquiring further qualifications and the returns they bring, if acquired, are considered separately for academic and vocational qualifications. 
What is of course very well-known is that individuals' social origins significantly condition their level of attainment within mainstream, full-time education, and in turn their eventual labour market positions. And, of late, the independent effect in these respects of individuals' cognitive ability has also been amply demonstrated (e.g. Feinstein and Bynner, 2004; Galindo-Rueda and Vignoles, 2005; Deary et al., 2007; Schoon, 2010; Staff et al., 2017; Authors). Although having a high level of ability is not enough to enable those from disadvantaged backgrounds to match the educational and labour market attainments of their more advantaged counterparts, it does go some way to mitigating the negative effects of their social origins (Authors). However, in the case of further education the situation is more complex. The questions arise of the ways in which social origins and cognitive ability may together affect the process of accumulating qualifications over the life-course, and differences in this regard could exist depending on whether academic or vocational qualifications are involved. Some research (Gloster et al., 2015; Authors) has indicated that individuals from more advantaged backgrounds - especially those with relatively low levels of initial qualification - are more likely to pursue further academic qualifications later in life, while those from less advantaged backgrounds are more likely to pursue further vocational qualifications; but in this research the possible role of cognitive ability is not considered.

To repeat, then, this paper focuses on the experience of lifelong learning for individuals who are from disadvantaged backgrounds and have a high level of cognitive ability, and we conceptualise the acquisition of further qualifications as a process. We use statistical methods that can express this process while also allowing for the effects of social origins and cognitive ability to be simultaneously considered. In this way, we believe, we are able to provide a more detailed analysis of one important aspect of the potential of lifelong learning than has previously been possible, not only in Britain, but also in other modern societies. 
We would, however, stress that we do not claim to demonstrate the actual mechanisms that causally link social origins, cognitive ability, further education and returns to further education. We seek only to establish empirical regularities at the level of associations. In this sense, our paper can be seen as exploratory: i.e., we follow Merton's (1987) argument (and cf. Goldthorpe, 2016: 14), that the first step in any sociological work is that of 'establishing the phenomena'. Specifying and testing the processes at the level of individual action and interaction that then generate the regularities observed would require data and analyses of different kinds to those we use in the present paper. But getting the explananda right to begin with is, we believe, essential.

Finally, we should note that we treat further education in terms of the formal, certified qualifications - both academic and vocational - that individuals obtain in the course of their working lives. We do so because formal qualifications would appear to be clearly more consequential than non-formal training for both intra- and intergenerational social mobility (e.g. Kilpi-Jakonen et al., 2015).

\section{Social origins, cognitive ability and life-long learning: two possibilities}

As earlier observed, it is commonly supposed in policy circles that the development of lifelong learning can open up opportunities for individuals disadvantaged in terms of their social origins, their initial educational attainment or their level of employment to upgrade their qualifications, and that it can thus contribute significantly to increasing upward social mobility both over the life-course and across generations. It is, indeed, quite conceivable that especially individuals of high cognitive ability, even if disadvantaged, could, with appropriate institutional provision, accumulate further qualifications during their working lives and in this way improve their 
mobility chances. In other words, one scenario is that of lifelong learning operating in a compensatory role, and in particular in regard to individuals whose educational potential has not previously been fully realised. If this scenario were prevalent, lifelong learning would indeed serve to increase intergenerational social mobility.

An alternative scenario is, however, also conceivable: lifelong learning could serve primarily to preserve the prevailing structure of inequalities via the logic of cumulative (dis)advantages. The idea behind the cumulative (dis)advantage thesis is simple: small initial differences among individuals tend to be magnified over time, for better or for worse (DiPrete and Eirich, 2006; Rigney, 2010). It thus becomes hard for individuals who 'fall behind', educationally or in their working lives, ever to catch up. Men and women from disadvantaged social origins who leave school with relatively low-level qualifications and enter the labour market in insecure, poorly paid jobs will have difficulty in finding the resources, even supposing they have the motivation, to pursue further education of a kind that could enhance their qualifications and thus their chances of upward mobility. In contrast, though, individuals from more advantaged origins who may, for whatever reason, have not performed well in full-time education and who have experienced downward mobility intergenerationally on entering the labour market could be expected to have the family resources necessary for them to take up opportunities for further education and also, following the theory of 'loss aversion', a strong motivation to do so - in order to avoid downward mobility being more pressing that to gain upward mobility (Kahneman, 2011: ch. 26; Gugushvili et al., 2017; Authors, forthcoming). For such individuals, further education can offer an important way of raising their qualification level and in turn achieving 'counter mobility' back to the position of their parents (cf. Goldthorpe, 2007; Bernardi and Ballarino, 2016; Erola and Kilpi-Jakonen, 2017). In this case, therefore, further 
education provides not a compensatory opportunity but rather one for 'recuperation' - for cumulative advantage to prevail if not in the short term then still in the longer term. If this alternative scenario were prevalent, lifelong learning would mainly serve to limit intergenerational social mobility.

As discussed in further detail below, the results presented in this paper will enable us to evaluate these two possible scenarios. Our focus on individuals from disadvantaged origins who are of high ability is intended to give, so to speak, the fairest chance to the compensatory scenario; for it is obviously with such individuals that this scenario is most likely to be realised.

\section{Data and variables}

We use data from the 1970 British Cohort Study (BCS70), a nationally-representative longitudinal panel survey which sampled over 17,000 children born in one week in $1970 .{ }^{1}$ We analyse a newly constructed dataset that contains rich information on cohort members' educational qualifications and employment histories between the ages of 16 - the earliest age at which cohort members could legally leave full-time education - and 38 - the latest age at which we have information for them. Our analyses are based on a reduced sample of 12,137 cohort members for whom we had information on their complete qualification and

\footnotetext{
${ }^{1}$ Appendix A provides further information on the survey.
} 
employment histories. We have conducted a multiple imputation exercise in order to compensate for the extent of missing data in our key variables. ${ }^{2}$

Dependent variables

Cohort members' qualifications histories include detailed information on all the academic and vocational qualifications that they had obtained in their working lives, up to age 38. For our purposes, we have created an ordered, eight-category classification of academic qualifications that ranges from 'no qualification' to 'postgraduate qualifications'. We use this classification for recording respondents' academic qualifications throughout their life-course. The UK vocational qualifications system is complex and, to simplify, qualifications are coded into the six-level National Vocational Qualifications (NVQ) classification, which allows an approximate cross-walk between academic and vocational qualifications. We use this classification for recording cohort members' vocational qualifications throughout their working lives. Table 1 describes the classifications of the academic and vocational qualifications that we work with.

\section{-- Table 1--}

As regards our first research question, we construct two dependent variables that we base on the two above classifications: cohort members' highest level of (1) academic and (2) vocational

\footnotetext{
${ }^{2}$ We describe our imputation models in Appendix C. The proportion of original cohort members excluded due to panel attrition is relatively low (below 10\%) and appears to be the result of operational shortcomings in data collection and coding procedures rather than of cohort members' non-response, and thus any associated biases should be minimised (Nathan, 1999).
} 
qualification, measured at yearly intervals between the completion of their first period of continuous full-time education - i.e., age 16 at the earliest - and age 38. In Figure 1, we plot cohort members' average level of attainment at each age. As is apparent, beyond the early-tomid-20s, when most individuals who continued on a full-time basis would complete tertiarylevel education, there is an essentially linear increase in attainment, for both academic and vocational qualifications. ${ }^{3} \mathrm{~A}$ further inspection of the data also reveals that more than half of the respondents (55\%) obtained some new qualification between leaving full-time education and age 38 - most of them did so via vocational rather than academic education. ${ }^{4}$ It is also apparent that the large majority of new qualifications (84\%) raised cohort members' highest level of qualification - as measured by the ordered classifications introduced in Table 1.

\section{-- Figure 1--}

As regards our second research question, we examine cohort members' social class positions at age 38, when they tend to reach a stage of 'occupational maturity' - i.e., when the probability of job changes implying changes of class position becomes negligible (cf. Authors). Class provides a more comprehensive indicator of individuals' economic standing than does current income level, since it can be shown to be associated with income security, short-term

\footnotetext{
${ }^{3}$ We also considered using a series of 'qualification thresholds' as alternative dependent variables. But since our previous research has shown (Authors) that the effects of social origins on the probability of obtaining new qualifications via life-long learning is essentially the same at each qualification threshold, we abandoned this idea.
}

\footnotetext{
${ }^{4}$ More specifically, $35 \%$ of the cohort members obtained only further vocational qualifications, $10 \%$ obtained only further academic qualifications and an additional 10\% obtained both.
} 
income stability and longer-term income prospect, as well as with wealth (Goldthorpe and McKnight, 2006; Authors, forthcoming). Further, in Britain, over-time increases in income inequality have occurred to a greater extent between, rather than within, social classes (Williams, 2013), and the intergenerational association between class position has been shown to be stronger than that between income level (Goldthorpe, 2013). We use a collapsed version of the National Statistics Socio-Economic Classification (NS-SEC) - see Table 2. We combine Classes 1 and 2 to form the salariat and Classes 6 and 7 to form the working class. But instead of collapsing Classes $3-5$, which is the conventional approach to creating a hierarchical measure of NS-SEC, we combine Classes 3 and 5, which we take to comprise 'intermediate' classes and we treat Class 4 - the small employers and own account workers - as a separate category. We do so because we know from previous research that educational qualifications do not play a strong role in access to self-employment (Ishida et al., 1995).

--Table 2--

Key explanatory variables

Consistently with the approach we have taken in previous work (Authors), we distinguish three components of social origins: parental class, status and education, each measured when cohort members were aged 10. Parental class is taken to represent family economic resources. As with cohort members, we begin with the seven-category NS-SEC which we then collapse as described below. Where both parents are in employment, we use the dominance method of determining parental class (Erikson, 1984). Parental status is taken to represent family sociocultural resources: parents' social networks and contacts and forms of cultural taste and participation (Chan, 2010). We use parents' occupations to assign them to the 31 categories of the Chan-Goldthorpe (2004) status scale, which is based on the occupational structure of 
close friendship; and we, again, use the dominance method in cases where both parents are in employment. Given that parental education is included in our analyses together with parental class and parental status, we take it as indicating the extent of the specific educational resources that parents have available to help their children; for example, their ability to provide their children with a favourable home learning environment and with informed guidance through the educational system in regards to choice of schools, subjects, courses and examinations to take (Authors). Parents are allocated a value on a seven-category scale, described in Appendix B, which takes into account the qualifications of both parents. The categories range from the lowest, in which neither parent has any qualification, to the highest, in which both have degree-level qualifications. Parental class, status and education are all known to produce both independent and cumulative effects on individuals' educational and labour market outcomes (Authors). The measure that we use here therefore considers all three components of social origins in combination. More precisely, we work with a three-fold collapse of parental class, and an approximation to tertiles for parental status and education. We then combine these, as shown in Appendix B Table B1, to create a three-category measure that distinguishes between cohort members originating in 'consistently advantaged', 'consistently disadvantaged' and 'intermediate' backgrounds.

As regards early-life cognitive ability, our measure is based on the four subtests of the British Ability Scales (BAS) that were administered to cohort members at age 10. Following what has now become the standard approach to measuring cognitive ability (Deary, 2001; Colom et al., 2002), we aim to capture the common variance across scores on these tests to derive a latent measure of general intelligence - otherwise termed ' $g$ '. For this purpose, we use principal 
components analysis, saving scores from the first component extracted. ${ }^{5}$ Many previous studies using BCS70 have taken the same approach (e.g., Galindo-Rueda and Vignoles, 2005; Schoon, 2008, 2010; Authors). Again, as with social origins, we work with a three-category measure - i.e., we derive tertiles of cognitive ability.

In treating our first research question, we include social origins and cognitive ability separately in the analysis, so that we can consider their independent effects on cohort members' qualification trajectories, as well as their interactions. But in treating our second research question, we create a variable that captures all nine combinations of our measures of social origins and cognitive ability. This allows us to isolate our main group of interest, individuals with a relatively high level of cognitive ability who come from consistently disadvantaged backgrounds, and to compare them to those coming from more advantaged backgrounds but with lower levels of ability.

In treating our second research question, we need to include variables that allow us to examine the effect of obtaining further qualifications on cohort members' social class attainment. Since in this case we are not concerned with the process of accumulating qualifications over the lifecourse, we simply use dummies to indicate whether or not respondents obtained any new academic or vocational qualifications that improved on their initial level of qualification, between leaving full-time education and age 38.

\section{Controls}

We include in all of our analyses cohort members' highest level of initial qualification, chiefly because we are interested in the role of further qualifications and so seek to strip out the

\footnotetext{
${ }^{5}$ See Appendix A for further information.
} 
influence of qualifications gained during the period of full-time education. Initial attainment is measured as the highest level of education, academic and vocational combined, achieved by respondents when they first left full-time education.

When addressing our first research question, we also include in the analysis cohort members' own social class position at each age, lagged by one year. We do this because we know from previous research that jobs in more advantaged classes typically provide enhanced opportunities for further education and training (Barnes, 2011; Dämmrich et al., 2014). We base this measure on the seven-class NS-SEC, but we add a further category for those who have never worked which, as expected, reduces in size with individuals' age.

Table B3 in Appendix B gives descriptive statistics for all of our key variables and controls.

\section{Results}

\section{Research question 1}

In treating our first research question, we begin with some descriptive statistics (Table 3). Echoing the results of past research, we find that individuals from consistently advantaged origins not only have, on average, a higher level of initial qualification than their less advantaged counterparts but they are also more likely to obtain new academic qualifications and less likely to obtain new vocational qualifications over their life-course. But early-life cognitive ability also matters. In each social origins group, high-ability individuals leave full-time education with a higher average level of qualification than lower-ability individuals, and the probability of obtaining further academic qualifications is also higher for them. In contrast, the probability of obtaining further vocational qualifications appears to be highest for individuals 
with middling level cognitive ability, although only for those who came from consistently advantaged or intermediate origins.

--Table 3--

We now proceed with modelling the process of individuals accumulating further qualifications over their life-course, and how far this differs by social origins and cognitive ability. For this purpose, we use multilevel growth curve modelling, an approach which is well-suited to situations in which the dependent variable takes on different values as a function of time. In our case, the dependent variable is cohort members' highest level of qualification at each age, which, as Figure 1 shows, increases monotonically as they grow older. With this technique, we can examine the effects of our key explanatory variables on respondents' initial level of qualification (intercepts), in addition to the shape of their growth trajectories (slopes). We can also examine between-person variability in patterns of change over the life-course (Curran et al., 2010). We run the models separately for our two dependent variables - i.e., the accumulation of academic and vocational qualifications. In Table 4, we summarise our main results, and we present the full sets of models in Appendix D, Tables D1 and D2. The fixed effects coefficients in Tables D1 and D2 represent the average linear trajectory ${ }^{6}$ for each explanatory variable - i.e. the pooling of all individual intercepts and slopes that comprise the groups captured by the different categories of the explanatory variables. Hereafter we refer to

\footnotetext{
${ }^{6}$ As Figure 1 shows, the process of accumulating qualifications is essentially linear over the age-range we consider. Nevertheless, as a robustness check, we re-ran a selected set of models with a quadratic term of age added to our equations. As Table D3 shows, the exponential terms never reach statistical significance; we therefore do not include them in our main analyses.
} 
this as the average level of each group. The random effects parameters, however, represent the variability in individual trajectories around these group means.

We begin with random intercepts models ( $\mathrm{MO}$ in Tables $\mathrm{D} 1$ and $\mathrm{D} 2$ ), in order to get a sense of the variability that needs to be explained. ${ }^{7}$ In the case of academic qualifications, we find that around $72 \%$ of the total unexplained variance is attributable to differences between individuals, and the remaining $28 \%$ is attributable to changes that occur over the course of individuals' lives. ${ }^{8}$ In the case of vocational qualifications, there is more life-course variability, with $38 \%$ of the total variance due to differences that occur over time. We then introduce a random slope ${ }^{9}$ for age in all subsequent models, which serves to reduce the remaining lifecourse variance for both dependent variables.

We now turn to Table 4, to discuss the main points of interest that emerge from our results. ${ }^{10}$

\footnotetext{
7 In a random intercepts-only model, we assume that each individual has a unique intercept, but their rates of progress (i.e., their slopes) are assumed to be identical.
}

${ }^{8}$ This is called the intra-class correlation (ICC), calculated by dividing the variance at the person level by the total variance: $\sigma_{u}^{2} / \sigma_{u}^{2}+\sigma_{e}^{2}$ where subscript $u$ refers to the individual level and subscript $e$ refers to the life-course level.

${ }^{9}$ By introducing a random slope for age, we relax the assumption that all individuals have the same rate of progress.

${ }^{10}$ In Tables D1 and D2, where we present our full models, we also show the results for our controls. As expected, individuals' initial level of qualification has a strong effect on their qualification trajectories. For academic qualifications, the higher the initial level, the more probable that individuals accumulate 
Model 1 clearly indicates that individuals with lower cognitive ability have, on average, a lower level of academic but a higher level of vocational qualification. As regards the effects of social origins, the patterns are, again, different for the two types of qualifications. Individuals coming from consistently advantaged backgrounds tend to have a higher level of academic qualification than those coming from consistently disadvantaged or intermediate backgrounds. In contrast, individuals in the latter group of origin have, on average, a significantly higher level of vocational qualification than either those coming from consistently advantaged or consistently disadvantaged backgrounds.

In Model 2, we examine the process of accumulating qualifications over the life-course; i.e., how steep or shallow the accumulation trajectories are for our three ability and three origin groups, given initial level of qualification. To do so, we add two sets of interactions to the model: between cognitive ability and age and between social origins and age. It is apparent that individuals with high level of cognitive ability have the steepest accumulation trajectories, both for academic and vocational qualifications - evidenced by the negative and statistically significant coefficients for the two lower ability groups. This means two things. First, highability individuals have, on average, the highest level of academic qualification (as shown in

further qualifications. But for vocational qualifications, those who leave full-time education with lowersecondary qualifications are the most likely to obtain new qualifications. Gender has no significant effect on the average level of academic attainment, but women do less well than men in the case of vocational attainment. And it is apparent that the higher an individual's class position, the higher their average level of either academic or vocational attainment. 
Model 1), in part because their initial level of qualification is above average and in part because they are more likely than their less able counterparts to obtain further academic qualifications in their working lives. Second, high-ability individuals have, on average, the lowest level of vocational qualification (as shown in Model 1) chiefly because they start out at a relatively low level and, although they are the most likely to accumulate further vocational qualifications over their life-course, this is not enough for them to catch up with their counterparts of middle- or low ability. Model 2 also shows that social origins do not affect the process of the accumulation of vocational qualifications - i.e. individuals coming from the intermediate social origins group have, on average, the highest level of vocational qualification (as shown in Model 1), primarily because they start out at the highest level. In contrast, in the case of academic qualifications, individuals from more advantaged backgrounds not only start out at a higher level, but they are also more likely than those from consistently disadvantaged backgrounds to obtain further academic qualifications during the course of their working lives - as indicated by the positive and statistically significant interactions.

But, for us, it is Models 3 and 4 that are of greatest relevance, as these are the models in which we examine the possibilities of further education either serving as a compensatory factor or contributing to cumulative (dis)advantages. As earlier indicated, it is conceivable that the effects of social origins on the average level of qualifications are moderated by cognitive ability. For example, it is possible that able individuals from consistently disadvantaged backgrounds obtain more qualifications over their working lives than less able individuals from more advantaged backgrounds - i.e., through lifelong learning opportunities they can compensate for the negative effects of their social origins. In order to investigate this possibility, we add two sets of interactions to the model: first, between social origins and cognitive ability (Model 
3); second, between social origins, cognitive ability and age (Model 4). The results we obtain, again, depend on the type of qualification. In the case of academic qualifications, we do not see much evidence of a compensatory effect. There are no statistically significant interactions in Model 3. And, Model 4, if anything, gives some support to the cumulative (dis)advantages thesis: i.e., given initial level of qualification, individuals of high ability coming from consistently advantaged origins appear to exhibit the steepest accumulation trajectories - as indicated by the negative and significant interactions. But in the case of vocational qualifications, we do see some evidence of compensation. That is, as Model 3 indicates, being of high ability serves to raise the average level of vocational qualification for individuals from consistently disadvantaged backgrounds while it serves to lower the average level of vocational qualifications for those from more advantaged social origins. Moreover, the positive and significant interaction effects in Model 4 imply that the accumulation trajectories are steeper for high-ability individuals from consistently disadvantaged backgrounds than for lower-ability individuals from any other background.

In order to illustrate our key results, we estimate the average level of academic and vocational qualification at each age, based on Model 4 in Table 4, for four groups of individuals: those of high ability from consistently advantaged and consistently disadvantaged backgrounds and those of low-ability from consistently advantaged and consistently disadvantaged backgrounds. We do the calculation separately for men and women. Figures 2 and 3 plot the estimates. As regards academic qualifications (Figure 2), we should first note that high-ability men and women from consistently advantaged backgrounds not only have a significantly higher level of qualification at each age than their counterparts from consistently disadvantaged backgrounds, but they also display a steeper accumulation trajectory - as 
Model 4 in Table 4 also indicated. Looking at the other extreme, individuals of low-ability from consistently disadvantaged backgrounds scarcely obtain any new academic qualification over their life-course - this group has the lowest initial attainment and the shallowest accumulation slope. Second, overall, we do not find significant differences in their accumulation trajectories - except for a very slight one with women - between high-ability individuals from consistently disadvantaged backgrounds and low-ability individuals from consistently advantaged backgrounds, suggesting that parental resources can countervail modest level of cognitive ability. Third, it is notable that the difference between the two extreme origin-ability groups in average level of academic qualification is magnified over the life-course: it essentially doubles between ages of 16 and 38 - a pattern that is much in line with the expectations of the cumulative (dis)advantages thesis.

--Figure 2--

As regards vocational qualifications, as Figure 3 shows, the accumulation trajectories are somewhat steeper than for academic qualifications. It is also apparent that the differences across the four origin-ability groups in average level of vocational attainment are less pronounced than that in average level of academic attainment. Still, there are some differences across the groups, chiefly along the following lines. High-ability individuals from consistently disadvantaged backgrounds and low-ability individuals from consistently advantaged backgrounds are roughly on a par in their average level of vocational qualification until around their mid-20s for women and late-20s for men, after which the disadvantaged but bright begin to pull further ahead - this being especially the case with women. On the other hand - similarly to what we observed for academic qualifications - less able individuals from consistently disadvantaged backgrounds have the shallowest accumulation trajectory. As a 
result, at age 38, the biggest variation in average level of vocational qualification is within the group of the consistently disadvantaged: those of high ability have the highest and those of low ability have the lowest level of qualification. We can then conclude that for vocational qualifications, no evidence of the cumulative (dis)advantages thesis shows up; instead, what we see is that through further education individuals can in fact to some extent compensate for disadvantaged origins.

--Figure 3--

In sum, in regard to our first research question, our results imply that bright individuals coming from consistently disadvantaged backgrounds are able to improve on their academic qualifications throughout lifelong learning, but to a lesser degree than their counterparts from consistently advantaged backgrounds. In other words, their high level of ability does not appear to be enough to compensate fully for their disadvantaged origins - to this extent the cumulative (dis)advantages scenario plays out. But our results also indicate that high ability individuals from disadvantaged backgrounds do improve through further education on their initial level of vocational qualifications and to a greater extent than their counterparts from more advantaged origin: i.e., in this respect, we do find evidence of further education effectively creating opportunity for compensation.

\section{Research question 2}

We now examine the role that further qualifications have in helping bright but disadvantaged individuals to achieve upward class mobility. 
We use multinomial logistic regression to model individuals' class attainment at age 38. More specifically, we examine the likelihood of being found in one of four different social class positions (cf. Table 2): the working class (Classes 6 and 7), the intermediate classes (Classes 3 and 5), the self-employed (Class 4) and the managerial and professional salariat (Classes 1 and 2). Attaining a position in the latter three could be considered upward mobility for the consistently disadvantaged. We have three key explanatory variables: a nine-category combined measure of social origins and cognitive ability plus two dummies indicating whether the cohort member obtained any further academic or vocational qualification between leaving full-time education and age 38 that raised their highest level of qualification. In addition, all models control for respondents' gender and initial level of qualification. Table 5 shows the average marginal effects (AMEs) of our key explanatory variables on the likelihood of individuals being found in different class positions. ${ }^{11}$

Three points of importance emerge.

First, over and above individuals' qualifications - initial or further - and their cognitive ability, social origins matter. Thus, those of high ability originating in advantaged backgrounds are significantly more likely than their counterparts from disadvantaged backgrounds to be found in the salariat, and are less likely to be found in the working class. Second, it is clear that cognitive ability also has an independent effect, especially for the consistently disadvantaged: if they are bright, they are much more likely to move up into the salariat. Third, we find that obtaining further academic, and to a lesser extent further vocational, qualifications does help

\footnotetext{
${ }^{11}$ The full results are presented in Appendix D, Table D4.
} 
individuals to avoid ending up in the working class and increases their probability of being found in the salariat.

--Table 5--

Now, in order to address our central concern with how far further education can help highability individuals from disadvantaged backgrounds to achieve intergenerational upward mobility, we estimate certain probabilities from an extension of the model of Table 5 which also includes interactions between obtaining further qualifications and the origin-ability groups. We focus on access to the salariat - i.e., on long-range upward mobility for those of consistently disadvantaged origins - and in Figure 4 we present the probabilities of being found in the salariat for men and women in our group of main interest and for members of four other origin-ability groups that provide the most revealing contrasts. ${ }^{12}$

\section{--Figure 4--}

It is evident that for high ability individuals from consistently disadvantaged social origins acquiring further academic qualifications is consequential. Those men and women in this group who obtain at least one new academic qualification between labour market entry and age 38 increase their chances of moving up into the salariat by around 15 percentage points as

\footnotetext{
12 We have also calculated the probabilities of individuals ending up in the intermediate classes and in the class of the self-employed (Figures D1 and D2 in Appendix D). The results are in line with those that we discuss in the text.
} 
compared with those who do not obtain such a qualification. ${ }^{13}$ It can also be seen that, given the acquisition of a further academic qualification, the likelihood of bright but disadvantaged individuals being found in the salariat is almost comparable to that of similarly high ability individuals from consistently advantaged backgrounds. In other words, for high ability individuals from disadvantaged backgrounds attaining academic qualifications through lifelong learning is, indeed, an important route to intergenerational upward mobility; and to this extent support for the compensatory scenario is provided. However, it has at the same time to be recalled that the probability of obtaining such qualifications is substantially lower for this group than for their counterparts from advantaged backgrounds (cf. Table 3 and Figure 2). Moreover, what can also be seen is a reverse situation in the case of vocational qualifications. High ability but disadvantaged individuals are the group most likely to obtain vocational qualifications via further education. But Figure 4 reveals that these qualifications have little effect in increasing chances of mobility into the salariat.

Finally, from Figure 4, it can be seen that while obtaining further academic qualifications does help to close the gap between individuals coming from advantaged and disadvantaged backgrounds in their probabilities of accessing the salariat, cognitive ability itself appears to have a 'direct' effect on individuals' class attainment. Those in our group of interest, the bright but disadvantaged, have a reasonably high chance to be found in the salariat, even if they do

\footnotetext{
${ }^{13}$ It can also be seen from Figure 4 that obtaining a new academic qualification makes an even bigger difference to the probability of ending up in the salariat for low ability men and women, and especially if they come from consistently disadvantaged origins. However, very few individuals are here involved (cf. Table 3 and Figure 2), and they may be subject to significant selection effects.
} 
not attain any new qualification, whether academic or vocational, over the course of their working lives. For example, if we take two men, both coming from consistently disadvantaged backgrounds but of differing ability, neither of whom has obtained further qualifications, the probability of accessing the salariat is around 50 percentage-points higher for the one of high ability than for the one of low ability. This indicates that acquiring further - academic qualifications is not the only way to achieve intergenerational upward mobility for high-ability individuals from disadvantaged backgrounds. Other ways evidently exist that would appear to be more directly related to cognitive ability.

\section{Conclusions}

In this paper, we have examined the extent to which lifelong learning can provide second chances for bright individuals coming from disadvantaged backgrounds by enabling them to achieve further qualifications that can in turn lead to intergenerational upward mobility. The extent of research undertaken in this area is still limited and, as far as we are aware, we provide the first attempt to explicitly factor in individuals' cognitive ability.

We use a newly constructed data-set derived from the 1970 British Birth Cohort study that includes detailed information on cohort members' qualification and employment histories. This cohort experienced substantial educational upgrading over their life-course, with the proportion holding no qualifications halving and the proportion holding qualifications above the upper-secondary level doubling over the age-range we consider.

We have envisaged two contrasting scenarios. We have considered, first, how far lifelong learning might operate in a compensatory role, in particular in regard to individuals from disadvantaged backgrounds whose educational potential has not previously been fully 
realised; and, second, how far lifelong learning could rather serve to preserve the prevailing structure of inequalities via the logic of cumulative (dis)advantage. We have sought to determine the extent to which these two scenarios play out by comparing the qualifications trajectories of bright individuals from disadvantaged backgrounds to their less able and more advantaged counterparts, and by investigating how far the returns, in terms of social class, to obtaining further qualifications differ across the groups in question.

Our results, first of all, clearly show that in analysing the associations existing between individuals' social origins, their cognitive ability and their acquisition of further qualifications through lifelong learning, the distinction between academic and vocational qualifications must be made.

In regard to academic qualifications, we find that bright individuals from disadvantaged origins do improve on their initial level of qualification, but not to the extent that they catch up with their more advantaged counterparts. Indeed, high-ability individuals coming from consistently advantaged origins have the highest level of initial attainment and accumulate new qualifications at the fastest rate thereafter. Further, we find no difference in their accumulation trajectories between high-ability individuals from consistently disadvantaged origins and low-ability individuals from consistently advantaged origins. The latter can be seen as pursuing further academic qualifications with the aim of achieving career advancement sufficient to avoid intergenerational downward mobility. What is then indicated is that while there is some evidence of lifelong learning having some compensatory role in providing opportunities for individuals who had not previously realised their full educational potential to acquire further academic qualifications, the cumulative (dis)advantages scenario is at the same time very much in operation. 
In regard to vocational qualifications, our results are on a quite different pattern. In this case, the bright but disadvantaged do in fact have the steepest accumulation trajectories - i.e., for high-ability individuals from disadvantaged backgrounds lifelong learning does in this way play a compensatory role in allowing these men and women to raise their level of qualification above that they attained in full-time education. But the question that then arises is that of the extent to which the qualifications they obtain are of value in helping them achieve intergenerational upward mobility.

Turning to the question of the class returns that qualifications from further education brings, we find that, in general, such qualifications do pay off, both in terms of reducing the risks of individuals ending up in the working class and of improving their chances of accessing the managerial and professional salariat. These returns are, however, much more pronounced for new academic than for new vocational qualifications. We find that the acquisition of further academic qualifications significantly improves the chances of upward mobility for those who are of high ability and from disadvantaged origins: the difference between this group and their counterparts from advantaged origins in the probability of entering the salariat is negligible among those who have obtained new academic qualifications. But new vocational qualifications do not have any similar effect. In other words, while the compensatory effect of further education is again in evidence, this effect can only be regarded as a limited one.

Moreover, we also show that over and above the effects of further qualifications on the mobility chances of individuals from disadvantaged backgrounds, there are substantial 'direct' effects of their level of cognitive ability. That is to say, obtaining further academic qualifications would appear to be only one channel for upward mobility for these individuals; there are others that appear more directly related to cognitive ability. For example, high ability 
individuals may be more successful in securing promotions in working life that do not necessarily require certified qualifications; they may successfully undertake job training that does not involve formal qualifications; or they may achieve upward mobility through selfemployment.

In sum, the dominant policy rhetoric that lifelong learning can provide second chances for disadvantaged individuals would appear somewhat exaggerated. The compensatory scenario receives some, but only limited, support from our research, while the cumulative (dis)advantage scenario is very clearly in evidence. To understand why policy in this regard has not more fully achieved its compensatory objectives, a further analysis would be required focusing on the actual causal mechanisms - the social processes - that underlie the empirical regularities that we have demonstrated.

One final issue that arises is that of how far the results we have reported are likely to apply in other national contexts. As far as we are aware, there are no studies from other countries that explicitly examine the links between social origins, cognitive ability, lifelong learning and social mobility - perhaps because of a lack of appropriate datasets. However, we think it quite possible that in certain respects our conclusions might not be generalizable, and in particular as regards vocational qualifications. As noted in the Introduction, participation in life-long learning is at a relatively high level in Britain, and this is predominantly directed towards obtaining new vocational qualifications. But, while high ability individuals from disadvantaged backgrounds are especially likely to accumulate such qualifications, they do little to improve these individuals' chances of intergenerational upward mobility, at least of a long-range kind. Evident considerations in explaining this are that in Britain the vocational educational and qualifications systems are not closely articulated with those of mainstream education, and that 
vocational qualifications do not in general have the same prestige or carry the same weight with employers as do academic qualifications. An obvious and potentially revealing contrast that could therefore be made would be with Germany, where vocational qualifications form an integral part of the national educational system, and highly institutionalised relations prevail between vocational qualifications, employment and class positions (see e.g., Klein, 2011). 


\section{References}

Appleby, Y., and Bathmaker, AM. (2006) The New Skills Agenda: Increased Lifelong Learning or New Sites of Inequality. British Educational Research Journal, 32:703-717.

Barnes, L. (2011) Education and Training. Social Trends 41. London: Office for National Statistics.

Beblavy, M., Thum, A.-E. and Potjagailo, G. (2014) Learning at Every Age? Lifecycle Dynamics of Adult Education in Europe. Studies in Continuing Education, 36:385-379.

Bernardi, F. and Ballarino, G. (eds.) Education, Occupation and Social Origin. Cheltenham: Edward Elgar. Blanden, J., Buscha, F., Sturgis, P. and Urwin, P. (2012) Measuring the Earnings Returns to Lifelong Learning in the UK. Economics of Education Review, 31:501-514.

Blossfeld, H. -P., Kilpi-Jakonen, E., Vono de Vilhena, D. and Buchholz, S. (2014) Adult Learning in Modern Societies: Patterns and Consequences of Participation from a Life-course Perspective. Cheltenham: Edward Elgar.

Chan, T.-W. and Goldthorpe, J. H. (2004) Is There a Status Order in Contemporary British Society? Evidence from the Occupational Structure of Friendship. European Sociological Review, 20:383-401.

Colom, R., Abad, F. J., Garcia, L. F. and Juan-Espinosa, M. (2002). Education, Wechsler's Full Scale and $\mathrm{g}^{\prime}$. Intelligence, 30:449-462.

Curran, P. J., Obeidat, K. and Losardo, D. (2010) Twelve Frequently Asked Questions about Growth Curve Modelling. Journal of Cognition and Development, 11:121-136.

Dämmrich, J., Vono de Vilhena, D. and Reichart, E. (2014) Participation in Adult Learning in Europe: The Impact of Country-Level and Individual Characteristics. In Blossfeld, H.-P. et al. (eds.) Adult Learning in Modern Societies: An International Comparison from a Life-Course Perspective. Cheltenham Edward Elgar.

Deary, I. J. (2001). Intelligence: A Very Short Introduction. Oxford: Oxford University Press.

Deary, I. J., Strand, S., Smith, P. and Fernandes, C. (2007) Intelligence and Educational Achievement. Intelligence, 35:13-21.

Desjardins, R. (2015) Participation in Adult Education Opportunities: Evidence from PIAAC and Policy Trends in Selected Countries. United Nations Educational, Scientific and Cultural Organisation. ED/EFA/MRT/2015/PI/02.

DiPrete, T. A., and Eirich, G. M. (2006) Cumulative Advantage as a Mechanism for Inequality: A Review of Theoretical and Empirical Developments. Annual Review of Sociology, 32: 271-297. 
Dorsett, R., Lui, S. and Weale, M. (2011) Estimating the Effect of Lifelong Learning on Women's Earnings using a Switching Model. London: Centre for Learning and Life Chances in Knowledge Economies and Societies.

Erikson, R. (1984) Social Class of Men, Women and Families. Sociology, 18:500-514.

Erikson, R. and Goldthorpe, J.H. (2010) Has Social Mobility in Britain Decreased? Reconciling Divergent Findings on Income and Class Mobility. British Journal of Sociology, 61:213-230.

Erola, J. and Kilpi-Jakonen, E. (eds.) (2017) Social Inequality Across the Generations The Role of Compensation and Multiplication in Resource Accumulation. Cheltenham: Edward Elgar.

Feinstein, L. and Binner, J. (2004) The Importance of Cognitive Development in Middle Childhood for Adult Socioeconomic Status, Mental Health and Problem Behaviour, Child Development, 75:13291339.

Galindo-Rueda, F. and Vignoles, A. (2005) The Declining Relative Importance of Ability in Predicting Educational Attainment, Journal of Human Resources, 40:335-353.

Gloster, R., Buzzeo, J., Marvell, R., Tassinari, A., Williamts, J., Williams, M., Swift, S. and Newton, B. (2015) The Contribution of Further Education and Skills to Social Mobility, London: BIS Research Paper no 254.

Goldthorpe, J.H. (2007) On Sociology, Volume II. Stanford University Press.

Goldthorpe, J.H. (2013) Understanding - and Misunderstanding - Social Mobility in Britain: the Entry of the Economists, the Confusion of Politicians and the Limits of Educational Policy. Journal of Social Policy, 42:431-50.

Goldthorpe, J.H. (2016) Sociology as a Population Science. Cambridge University Press.

Goldthorpe, J. H. \& McKnight, A. (2006) The Economic Basis of Social Class, in S. Morgan, D. B. Grusky and G. S. Fields (Eds.) Mobility and Inequality: Frontiers of Research from Sociology and Economics. Stanford University Press.

Gugushvili, A., Bukodi, E. and Goldthorpe, J.H. (2017) The direct effect of social origins on social mobility chances: 'Glass floors' and 'glass ceilings' in Britain. European Sociological Review, 33: 305-316.

Ishida, H., Müller, W. and Ridge, J. (1995) Class Origin, Class Destination and Education: A Cross-National Study of Industrial Relations. American Journal of Sociology, 101:145-193.

Jenkins, A. (2017) Adult Learning and Qualifications in Britain. Journal of Education and Work, 30:445455.

Jenkins, A. (2013) Learning and the Life-course: The Acquisition of Qualifications in Adulthood, CLS Cohort Studies Working Paper No. 2013/4. 
Jenkins, A., Vignoles, A., Wolf, A. and Galindo-Rueda, F. (2003) The Determinants and Labour Market Effects of Lifelong Learning. Applied Economics, 35:1711-1721.

Jensen, A. R. (1998) The g Factor: The Science of Mental Ability. Westport, CT: Praeger.

Kahneman, D. (2011) Thinking Fast and Slow. London: Penguin.

Kilpi-Jakonen, E., Vono de Vilhena, D. and Blossfeld, H-P. (2015) Adult Learning and Social Inequalities: Process of Equalisation or Cumulative Disadvantage? International Review of Education, 61:529-546.

Klein, M. (2011) Trends in the Association between Educational Attainment and Class Destinations in West Germany. Research in Social Stratification and Mobility, 29:427-444.

Merton, Robert K. (1987) Three Fragments from a Sociologist's Notebooks: Establishing the Phenomenon, Specified Ignorance, and Strategic Research Materials. Annual Review of Sociology 13: $1-29$

Nathan, G. (1999) A Review of Sample Attrition and Representativeness in Three Cohort Studies. London: Governmental Statistical Service Methodological Series, 13.

Riddell, S. and Markowitsch, J. (2012) Lifelong Learning in Europe: Equity and Efficiency in the Balance. Bristol: Policy Press.

Rigney, D. (2010) The Matthew Effect: How Advantage Begets Further Advantage, Columbia University Press.

Schoon, I. (2008). A Transgenerational Model of Status Attainment: The Potential Mediating Role of School Motivation and Education, National Institute Economic Review, 205:72-82.

Schoon, I. (2010). Childhood Cognitive Ability and Adult Academic Attainment: Evidence from Three British Cohort Studies, Longitudinal and Life Course Studies, 1:241-258.

Staff, R.T., Hogan, M.J. and Whalley, L.J. (2017) Childhood Intelligence and Personality Traits Neuroticism and Openness Contributes to Social Mobility: A Study in the Aberdeen 1936 Birth Cohorts, Personality and Individual Differences, 114:206-212.

Williams, M. (2013) Occupations and British Wage Inequality, 1970s-2000s. European Sociological Review, 29:841-857.

Wolf, A. (2011) Review of Vocational Education - The Wolf Report. Government of the UK: Department of Business, Innovation and Skills and Department for Education.

Wolf, A., Jenkins, A. and Vignoles, A. (2006) Certifying the Workforce: Economic Imperative or Failed Social Policy? Journal of Education Policy, 21:535-565. 
Tables and Figures 
TABLE 1. The two qualification classifications

Description

Academic qualifications

1. No qualifications

2. Sub-secondary

Below O-level or GCSE

3. Lower secondary - low performance

1-4 O-level or GCSE passes

4. Lower secondary - high performance or

5+ O-level or GCSE passes or 1

higher secondary - low performance

A-level pass

5. Higher secondary - high performance

$2+$ A-level passes

6. Lower tertiary

Tertiary sub-degree

qualification

7. Higher tertiary

Degree

8. Postgraduate

Masters degree, $\mathrm{PhD}$

Vocational qualifications

1. No qualifications

2. Sub-secondary

NVQ1

3. Lower secondary

NVQ2

4. Higher secondary

NVQ3

5. Lower tertiary

NVQ4

6. Higher tertiary

NVQ5-6 
FIGURE 1: Average level of academic and vocational qualification at each age

Academic qualifications ${ }^{(a)}$

Average level of

academic

qualification

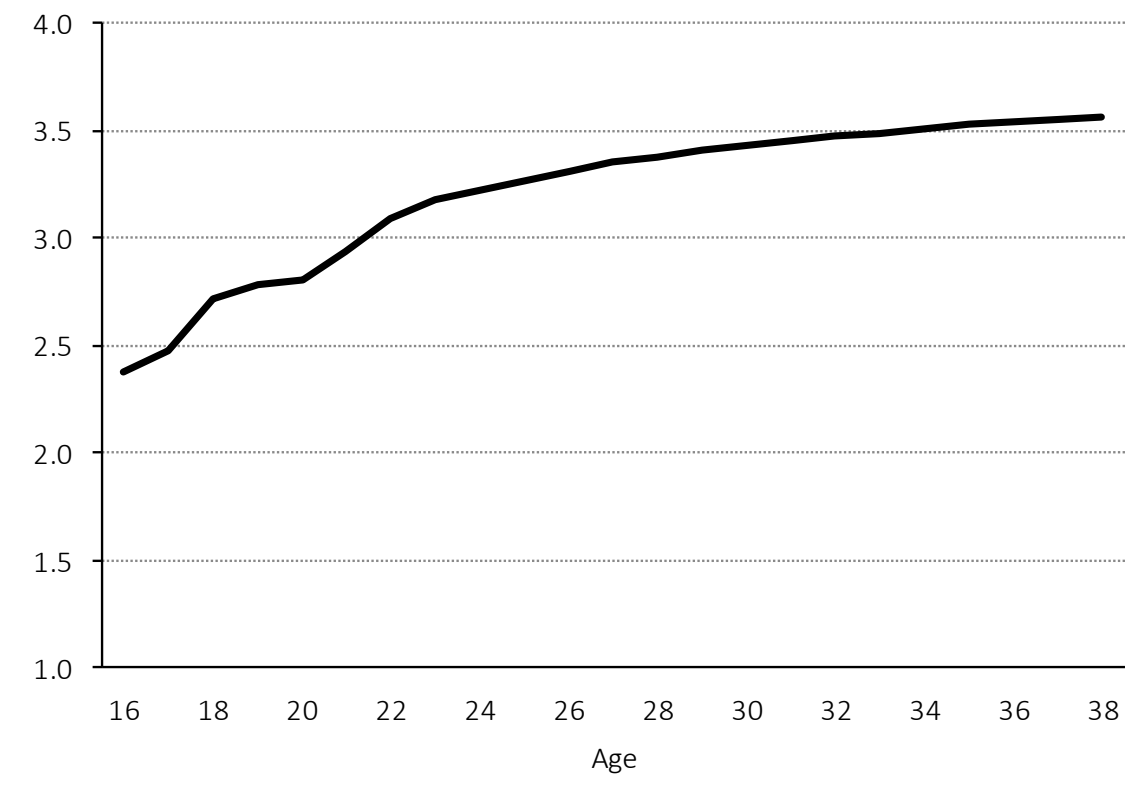

Notes:

(a): Scale: 1-8

(b): Scale: 1-6
Vocational qualifications ${ }^{(b)}$

Average level of

vocational

qualification

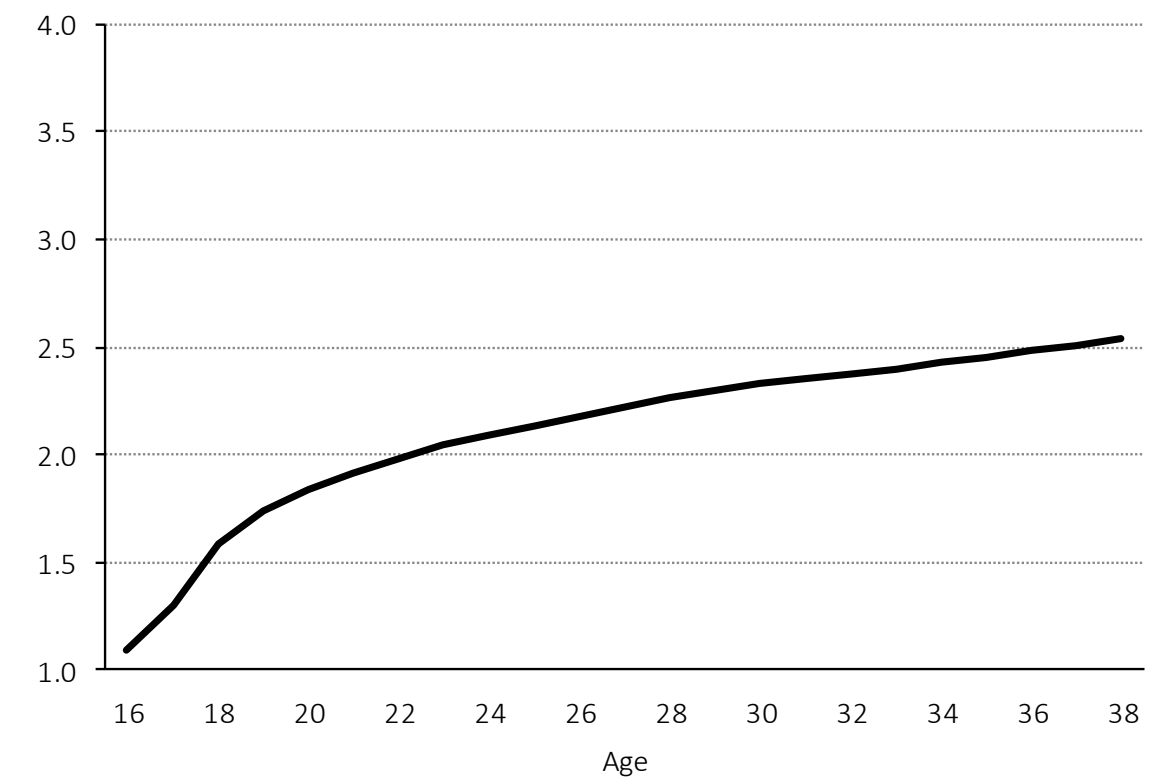


TABLE 2: Cohort members' social class positions at age 38: derivation and distribution

\begin{tabular}{|c|c|c|c|c|}
\hline & Seven-class NS-SEC & & Four-class NS-SEC & $\%$ \\
\hline $\begin{array}{l}\text { Class } 1 \\
\text { Class } 2\end{array}$ & $\begin{array}{l}\text { Higher managers and professionals } \\
\text { Lower managers and professionals }\end{array}$ & 1 & Salariat & 38.3 \\
\hline $\begin{array}{l}\text { Class } 3 \\
\text { Class } 5\end{array}$ & $\begin{array}{l}\text { Ancillary professional and administrative } \\
\text { Lower supervisory and technical occupations }\end{array}$ & 2 & Intermediate classes & 22.5 \\
\hline Class 4 & Small employers and own account workers & 3 & Small employers and own account workers & 10.4 \\
\hline $\begin{array}{l}\text { Class } 6 \\
\text { Class } 7\end{array}$ & $\begin{array}{l}\text { Semi-routine occupations } \\
\text { Routine occupations }\end{array}$ & 4 & Working class & 28.8 \\
\hline
\end{tabular}


TABLE 3: Average level of initial qualification (with standard deviation) and proportion of cohort members obtained further qualifications (with 95\% confidence intervals), by social origins and cognitive ability

\begin{tabular}{|c|c|c|c|c|c|c|c|}
\hline \multirow[b]{2}{*}{ Consistently disadvantaged origins } & \multirow{2}{*}{$\begin{array}{c}\begin{array}{c}\text { Average level } \\
\text { of initial }\end{array} \\
\text { qualification }^{(a)} \\
2.4[1.6]\end{array}$} & \multicolumn{6}{|c|}{$\begin{array}{l}\% \text { of cohort members obtained further ... } \\
\text { academic } \quad \text { vocational }\end{array}$} \\
\hline & & [11.0] & 12.2 & [13.6] & [43.6] & 45.5 & {$[47.5]$} \\
\hline ... low level of cognitive ability & $2.0[1.3]$ & [7.1] & 8.7 & {$[10.5]$} & [38.8] & 41.7 & {$[44.7]$} \\
\hline ... middle level of cognitive ability & $2.5[1.6]$ & [11.7] & 14.1 & {$[17.0]$} & [46.3] & 50.1 & {$[53.8]$} \\
\hline ... high level of cognitive ability & $3.2[1.8]$ & [17.4] & 21.4 & {$[26.0]$} & {$[46.7]$} & 52.0 & {$[57.2]$} \\
\hline Intermediate origins & $3.0[1.9]$ & [17.8] & 18.8 & [19.9] & [46.1] & 47.4 & {$[48.7]$} \\
\hline ... low level of cognitive ability & $2.3[1.5]$ & [8.6] & 10.1 & [11.8] & [42.5] & 45.2 & {$[47.8]$} \\
\hline ... middle level of cognitive ability & $3.0[1.8]$ & [19.0] & 19.0 & [21.1] & [48.8] & 51.4 & {$[53.9]$} \\
\hline ... high level of cognitive ability & $3.8[2.1]$ & [25.5] & 27.9 & {$[30.4]$} & [43.6] & 46.4 & {$[49.1]$} \\
\hline Consistently advantaged origins & $4.3[2.2]$ & [28.1] & 29.9 & [31.7] & [39.3] & 41.3 & {$[43.2]$} \\
\hline ... low level of cognitive ability & $2.9[1.8]$ & [17.0] & 21.4 & {$[26.6]$} & [36.6] & 32.2 & {$[47.9]$} \\
\hline ... middle level of cognitive ability & $3.7[2.0]$ & [24.3] & 27.8 & [31.5] & [43.9] & 47.9 & {$[51.9]$} \\
\hline ... high level of cognitive ability & $5.0[2.1]$ & [31.9] & 34.6 & {$[37.4]$} & [36.0] & 38.8 & {$[41.7]$} \\
\hline Low level of cognitive ability & $2.2[1.5]$ & [9.6] & 10.6 & [11.8] & [41.3] & 43.1 & {$[44.9]$} \\
\hline Middle level of cognitive ability & $3.0[1.8]$ & [18.4] & 19.8 & [21.3] & [48.7] & 50.5 & {$[52.3]$} \\
\hline High level of cognitive ability & $4.2[2.2]$ & [27.1] & 28.7 & {$[30.3]$} & [42.3] & 44.1 & {$[45.9]$} \\
\hline Total & $3.1[2.0]$ & [19.1] & 19.8 & {$[20.5]$} & [44.0] & 44.9 & [45.7] \\
\hline
\end{tabular}

Note:

(a): scale: $1-8$ 
TABLE 4: Effects of cognitive ability and social origins on cohort members' accumulation of qualifications between leaving full-time education and age 38 - results from growth curve modelling

\begin{tabular}{|c|c|c|c|c|c|c|c|c|}
\hline & \multicolumn{4}{|c|}{ Academic qualifications } & \multicolumn{4}{|c|}{ Vocational qualifications } \\
\hline & M1 & $\mathrm{M} 2$ & M3 & M4 & M1 & $\mathrm{M} 2$ & M3 & M4 \\
\hline \multicolumn{9}{|l|}{ Cognitive ability } \\
\hline Low & $-0.142 * * *$ & $0.669 * * *$ & $0.687^{* * *}$ & $0.450 * * *$ & $0.103^{* * *}$ & ${ }^{*} 0.338^{* * *}$ & $0.214^{* * *}$ & $0.344^{* * *}$ \\
\hline Middle & $-0.078 * * *$ & $0.433^{* * *}$ & $0.445^{* * *}$ & $0.267^{* * *}$ & $0.095^{* * *}$ & $0.166^{* * *}$ & 0.069 & $0.169 *$ \\
\hline \multicolumn{9}{|l|}{ High (ref.) } \\
\hline \multicolumn{9}{|l|}{ Social origin } \\
\hline \multicolumn{9}{|l|}{ Consistently disadvantaged (ref.) } \\
\hline Intermediate & 0.006 & $-0.191^{* * *}$ & $-0.167 * *$ & $-0.336 * *$ & $0.053 * *$ & 0.021 & -0.076 & 0.016 \\
\hline Consistently advantaged & $0.096^{* * *}$ & $-0.587^{* * *}$ & $-0.584^{* * *}$ & $-0.830^{* * *}$ & 0.004 & -0.044 & $-0.169 * *$ & -0.031 \\
\hline \multicolumn{9}{|l|}{ Ability * Age } \\
\hline Low * Age & & $-0.042^{* * *}$ & $-0.042^{* * *}$ & $-0.030^{* * *}$ & & $-0.014^{* * *}$ & $-0.014^{* * *}$ & $-0.021 * * *$ \\
\hline Middle * Age & & $-0.027^{* * *}$ & $-0.027^{* * *}$ & $-0.017^{* * *}$ & & $-0.004 *$ & $-0.004 *$ & $-0.010 *$ \\
\hline \multicolumn{9}{|l|}{ Origin *Age } \\
\hline Intermediate ${ }^{*}$ Age & & $0.010 * * *$ & $0.010^{* * *}$ & $0.019 * * *$ & & 0.002 & 0.002 & -0.003 \\
\hline Consistently advantaged * Age & & $0.036 * * *$ & $0.036 * * *$ & $0.048^{* * *}$ & & 0.003 & 0.002 & -0.005 \\
\hline \multicolumn{9}{|l|}{ Origin * Ability } \\
\hline Intermediate * Low & & & -0.033 & 0.197 & & & $0.139 *$ & -0.001 \\
\hline Intermediate * Middle & & & -0.027 & 0.130 & & & 0.088 & 0.017 \\
\hline Consistently advantaged * Low & & & 0.001 & $0.489^{* * *}$ & & & $0.194^{* *}$ & 0.001 \\
\hline Consistently advantaged * Middle & & & 0.013 & $0.290 *$ & & & $0.157 *$ & -0.044 \\
\hline \multicolumn{9}{|l|}{ Origin * Ability * Age } \\
\hline Intermediate ${ }^{*}$ Low $*$ Age & & & & -0.012 & & & & 0.008 \\
\hline Intermediate $*$ Middle $*$ Age & & & & -0.008 & & & & 0.004 \\
\hline Consistently advantaged * Low * Age & & & & $-0.025^{* * *}$ & & & & $0.011 *$ \\
\hline Consistently advantaged * Middle * & Age & & & $-0.014 *$ & & & & $0.012 *$ \\
\hline
\end{tabular}

Notes:

(a) Controls and random slope for age are included.

(b) *** $\mathrm{p}<0.001$; ** $\mathrm{p}<0.01 ; * \mathrm{p}<0.05$ 
FIGURE 2: Estimated average level of academic qualification (with 95\% confidence intervals) at each age, by social origins and cognitive ability $^{(a)(b)}$

Men

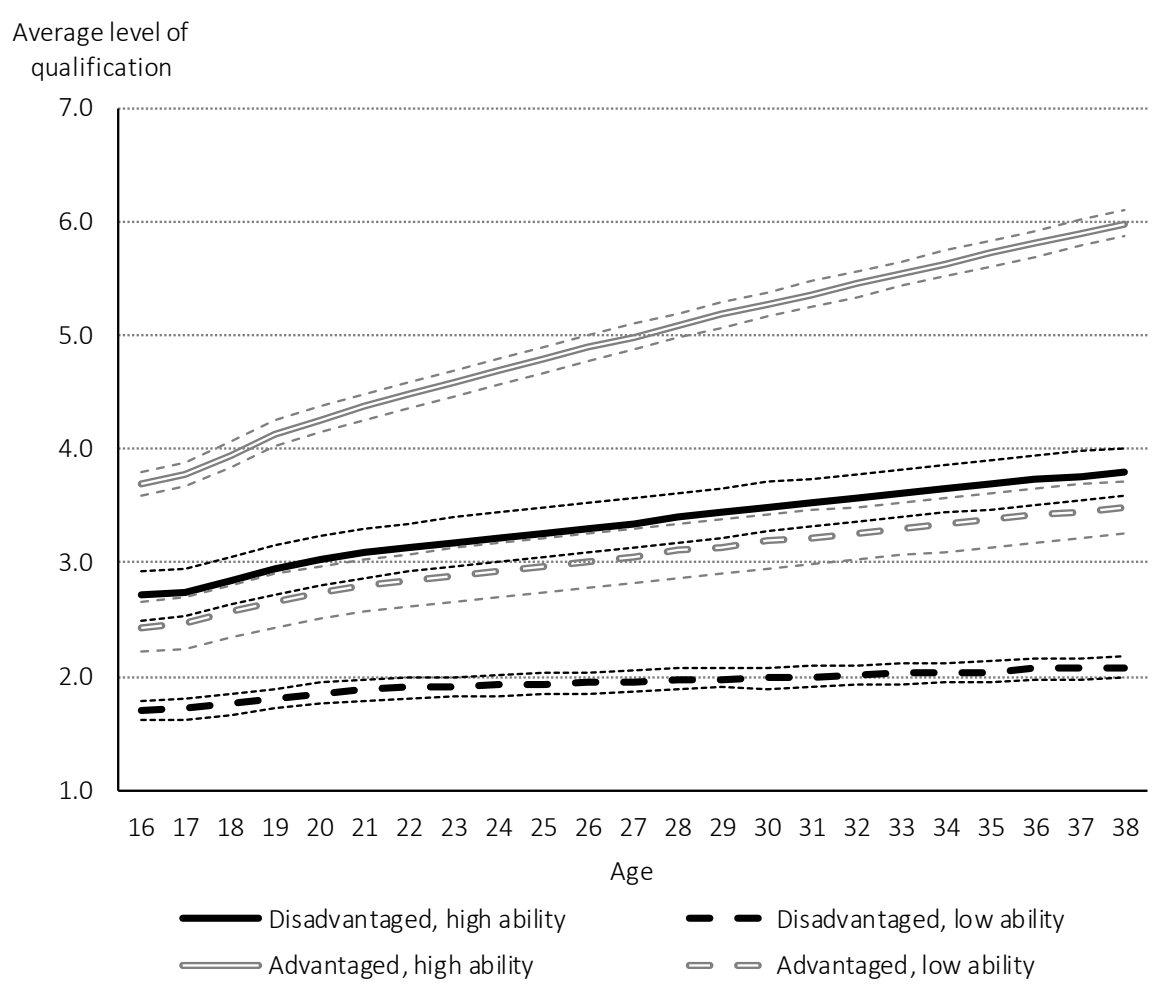

Note

(a): Based on Model 4 in Table 4; model run separately by gender.

(b): Scale: $1-8$
Women

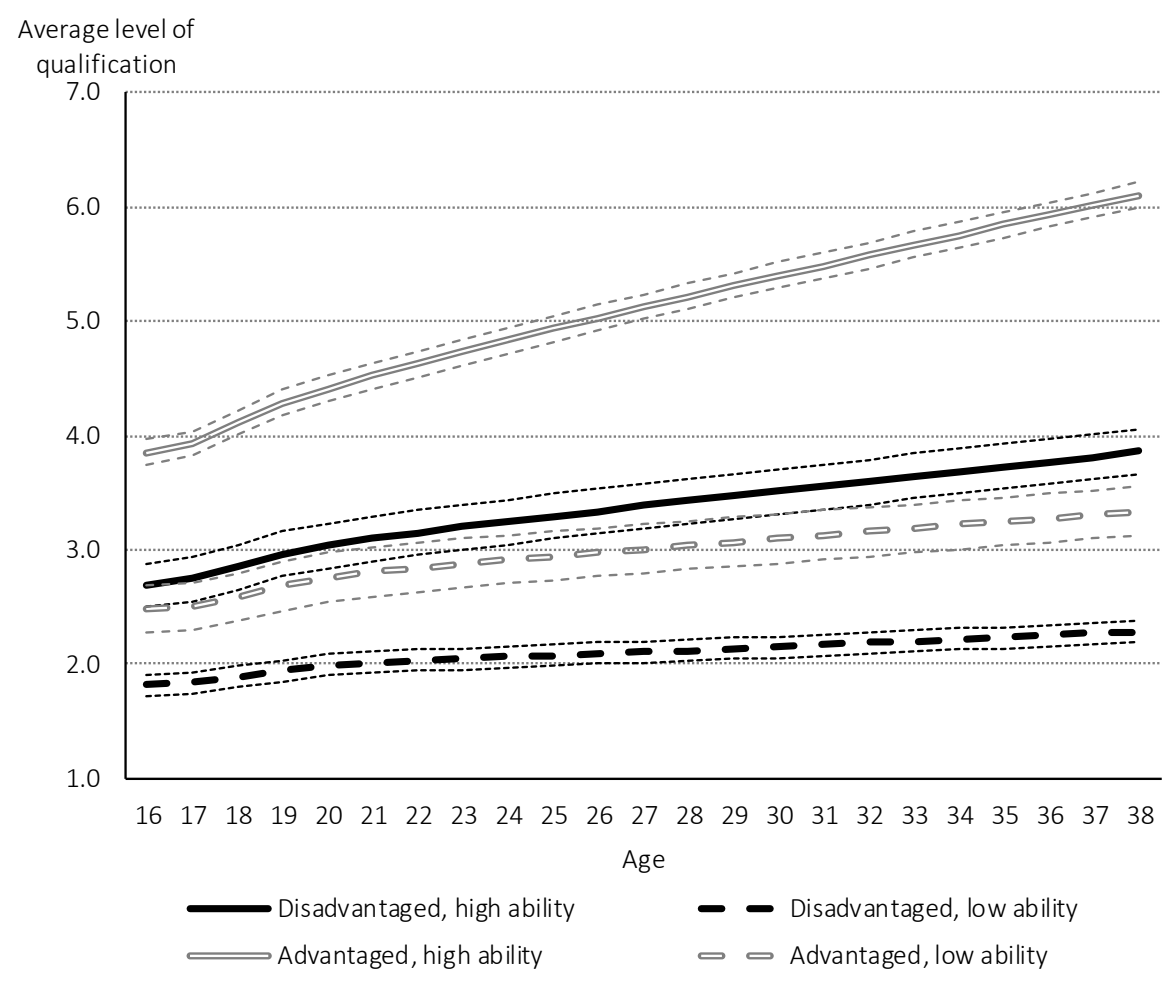


FIGURE 3: Estimated average level of vocational qualification (with $95 \%$ confidence intervals) at each age, by social origins and cognitive ability $^{(a)(b)}$

Men

Average level of

qualification

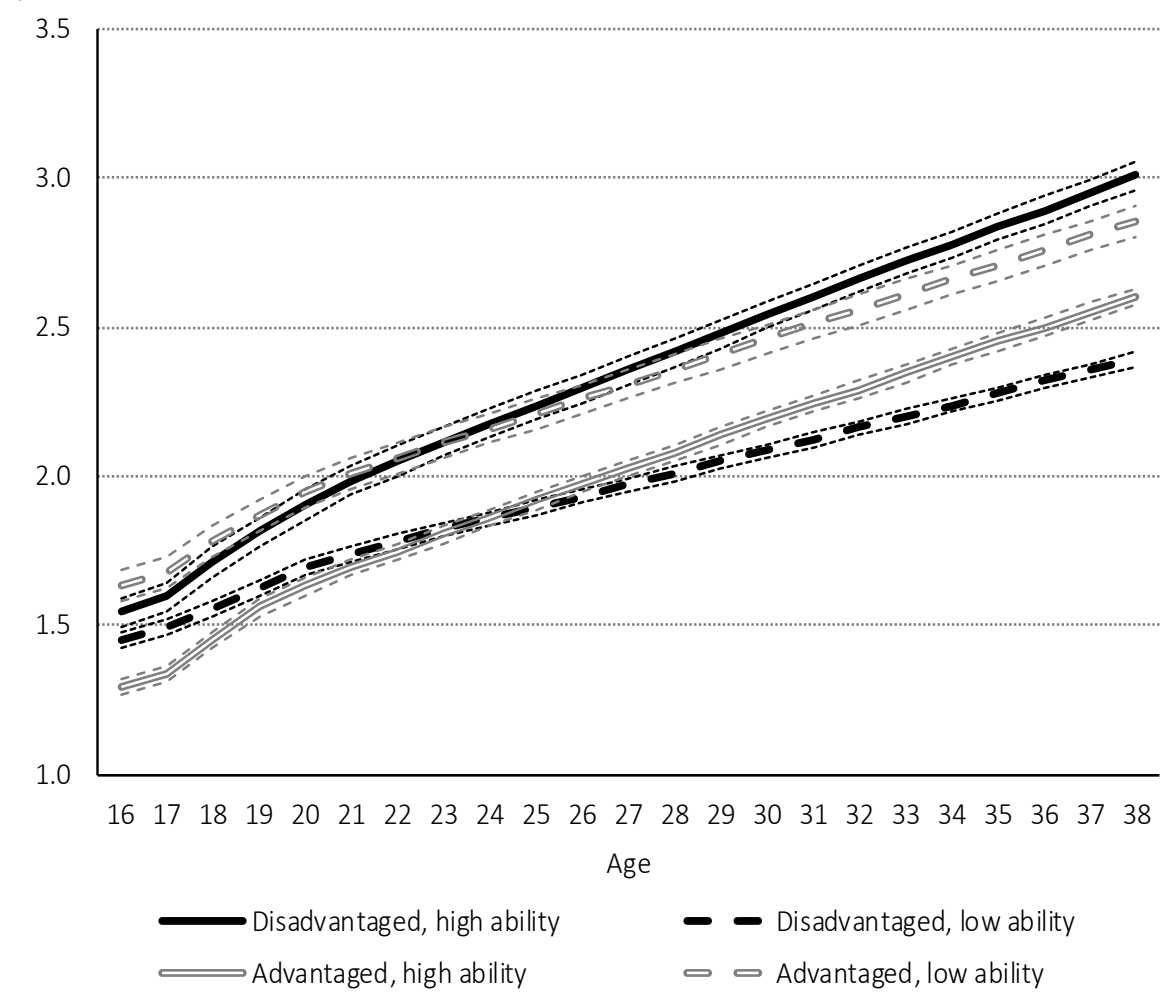

Note

(a): Based on Model 4 in Table 4; model run separately by gender.

(b): Scale: 1-6

\section{Women}

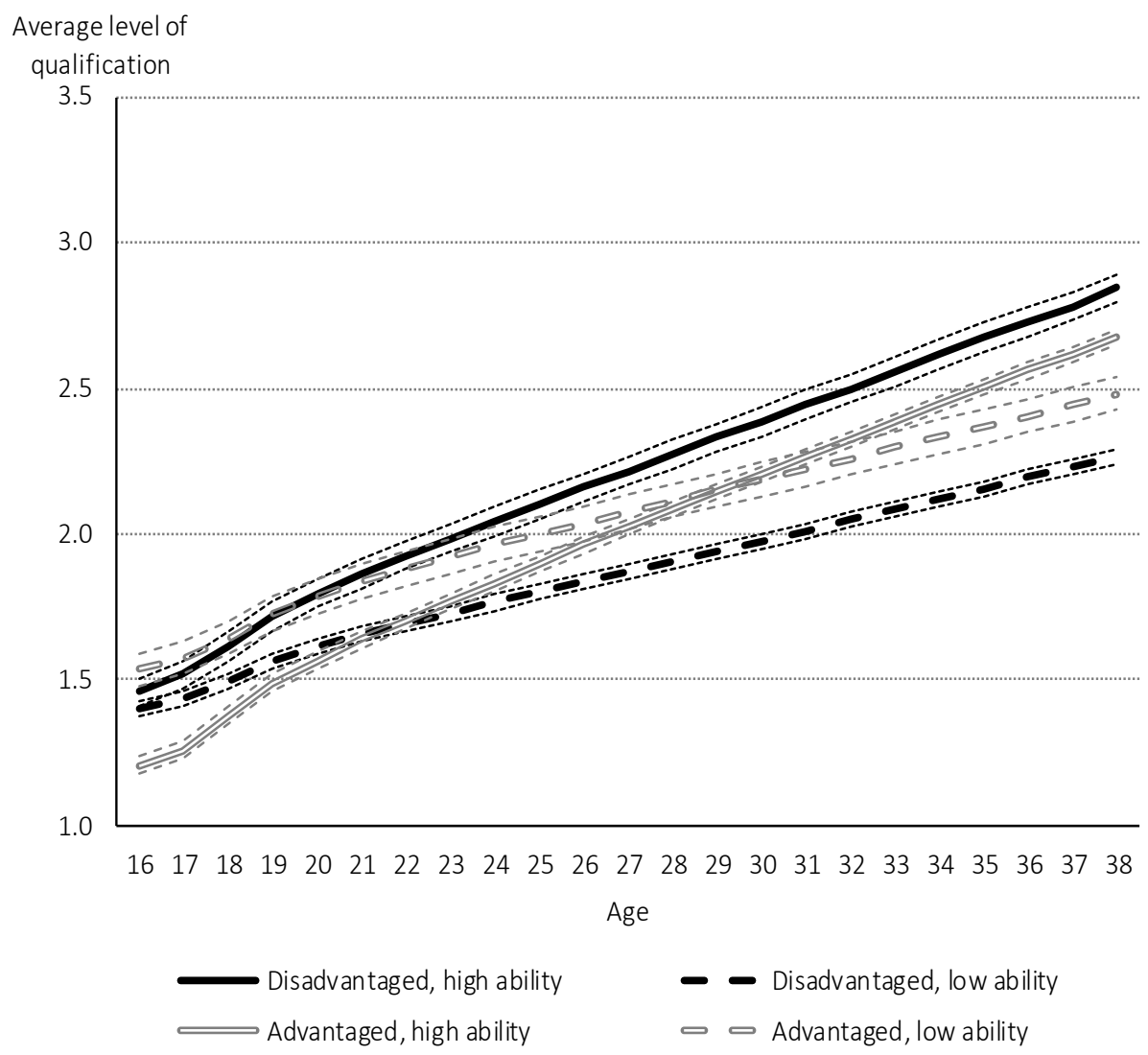


TABLE 5: Effects of social origins, cognitive ability and further qualifications on the probability of being found in different class positions at age 38 (AMEs, \%)

\begin{tabular}{|c|c|c|c|c|}
\hline & \multicolumn{4}{|c|}{ Class position at age 38} \\
\hline & Salariat & $\begin{array}{r}\text { Intermediate } \\
\text { classes }\end{array}$ & $\begin{array}{r}\text { Self- } \\
\text { employed }\end{array}$ & $\begin{array}{l}\text { Working } \\
\text { classes }\end{array}$ \\
\hline \multicolumn{5}{|l|}{ Social Origins, Cognitive ability } \\
\hline Disadvantaged, low ability & $-14.32 * * *$ & -0.27 & 0.62 & $13.97 * * *$ \\
\hline Disadvantaged, middle ability & $-8.82 * *$ & 1.31 & 0.07 & $7.43 * *$ \\
\hline Disadvantaged, high ability (ref) & 0.00 & 0.00 & 0.00 & 0.00 \\
\hline Intermediate, low ability & $-9.11 * *$ & 0.80 & 1.96 & $6.35 *$ \\
\hline Intermediate, middle ability & -2.17 & 3.59 & 1.12 & -2.54 \\
\hline Intermediate, high ability & 4.64 & 0.68 & -0.11 & -5.21 \\
\hline Advantaged, low ability & -3.27 & -0.69 & 2.55 & 1.40 \\
\hline Advantaged, middle ability & 2.28 & 1.21 & 0.62 & -4.11 \\
\hline Advantaged, high ability & $8.77^{* *}$ & -1.10 & 0.20 & $-7.84^{* *}$ \\
\hline \multicolumn{5}{|l|}{ Further qualification obtained... } \\
\hline Academic $(=1$, otherwise $=0)$ & $19.93 * * *$ & $-2.68 *$ & $-2.46 *$ & $-14.79 * * *$ \\
\hline Vocational $(=1$, otherwise $=0)$ & $3.01 * *$ & $2.50 *$ & 0.60 & $-6.11 * * *$ \\
\hline
\end{tabular}

Notes:

(a) Controls are included for gender and highest level of qualification when leaving fulltime education.

(b) ${ }^{* * *} p<0.001 ; * * p<0.01 ; * p<0.05$ 
FIGURE 4: Estimated probability (with 95\% confidence interval) of cohort members being found in the salariat at age 38 by social origins and cognitive ability, for those obtaining or not obtaining further academic or vocational qualification since leaving full-time education ${ }^{(a)}$

Men

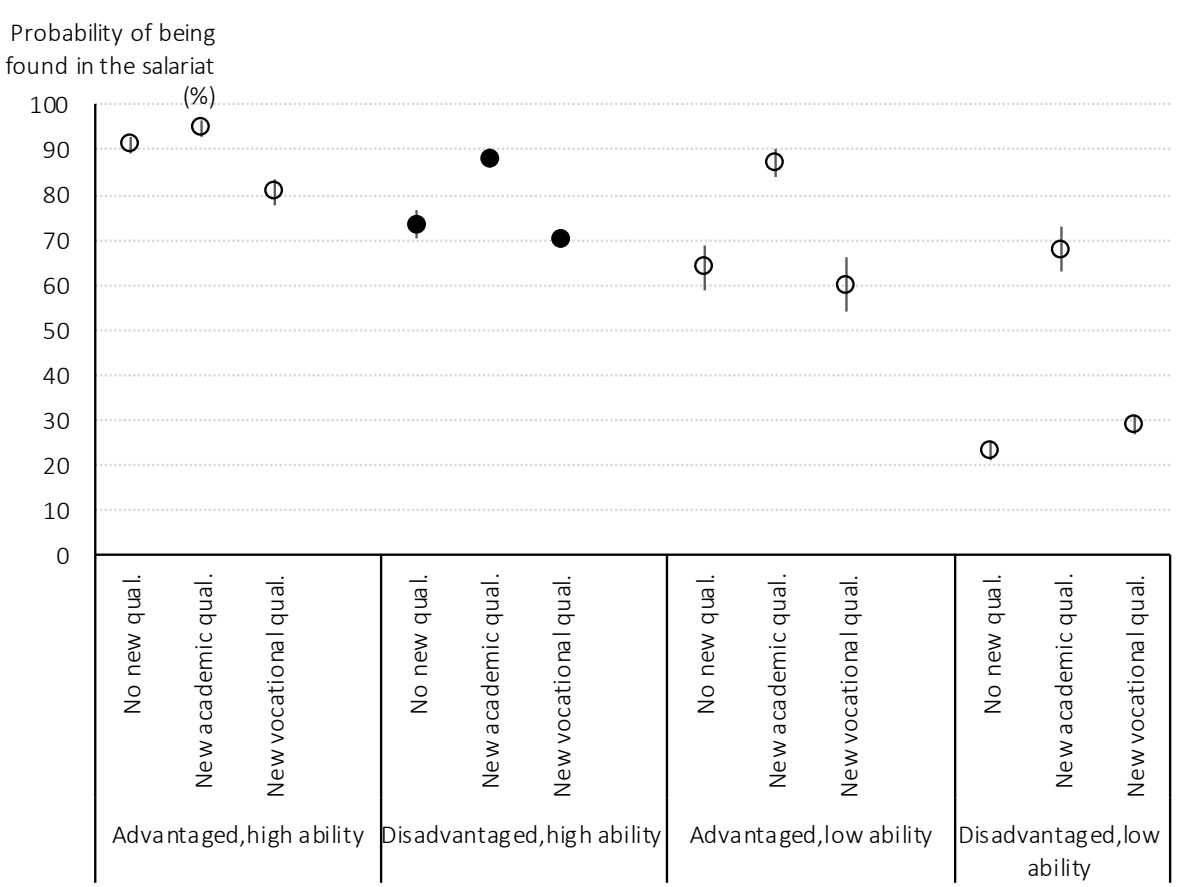

Women

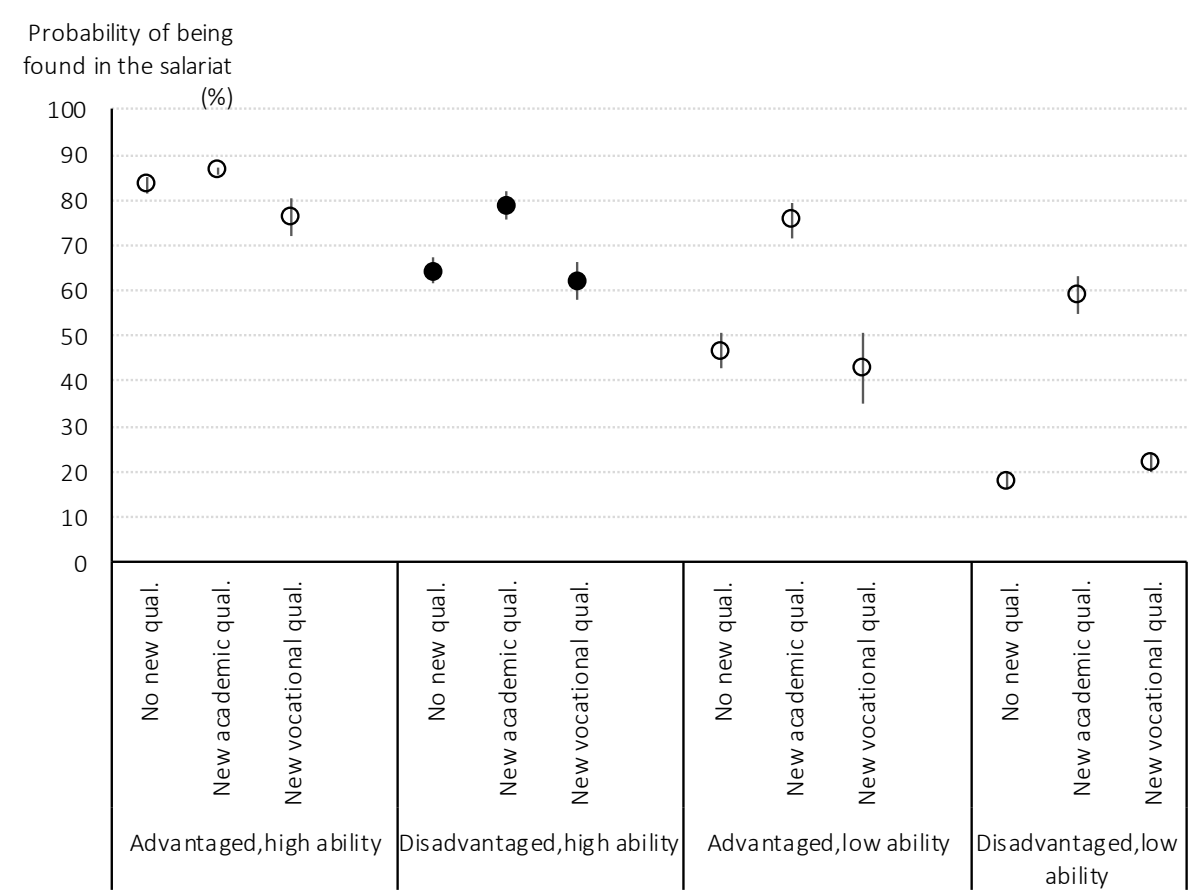

Note

(a): Based on an extension of the model in Table 5 that also includes interactions between further qualifications and the origin-ability groups; model run separately by gender. 


\title{
Cognitive ability, life-long learning and social mobility in Britain: Do further qualifications provide second chances for bright people from disadvantaged backgrounds?
}

\author{
Erzsébet Bukodi, Mollie Bourne, Bastian Betthäuser
}

\begin{abstract}
Appendix
Appendix A: Introducing BCS70

The 1970 British Cohort Study (BCS70) is a longitudinal study which began collecting data on 17,198 babies born in England, Scotland, Wales and Northern Ireland in a particular week in April 1970 (specifically, from 00.01 hours on Sunday, 5th April to 24.00 hours on Saturday, 11th April, 1970). It was estimated that not more than five percent and not less than two percent of the births during this week in in England, Scotland, Wales and Northern Ireland have been missed and are therefore not present in the survey.

After the initial birth survey, Northern Irish participants were dropped from the sample. The surveys at ages 5 and 10 augmented their samples by adding immigrants born in the same week. Consequently, the sample only includes immigrants who moved to Britain before the age of 16, as there were no attempts to include further members beyond the age 16 survey in 1986. Since the birth survey in 1970, there have been eight 'sweeps' of all cohort members at ages $5,10,16,26,30,34,38$ and 46 . With each successive sweep of data collection, the scope of enquiry has broadened from a strictly medical focus at birth, to encompass physical and educational development at the age of five, physical, educational and social development.

At each sweep, different sources and methods were used to gather information on the cohort members. In the birth survey, the midwife present at the birth completed a questionnaire and supplementary information was obtained from clinical records. As the cohort members got older, the tools and information gathered changed. Health Visitors interviewed the parents, teachers completed questionnaires, medical examinations were carried out, and cohort members themselves participated in educational assessments. In certain sweeps, cohort members have also kept nutrition and activity diaries.

Table A1 shows the development of the number of participants across the different waves of data collection. Note that a large share of the reduction in the sample size between Wave 1 and Wave 2 may be due to the exclusion of individuals born in Northern Ireland after the first sweep of data collection. The documentation for Wave 3 from which information on parental characteristics was taken concludes that the achieved sample in 1980 does not differ greatly from the birth sample in 1970 with respect to several key characteristics.
\end{abstract}


Table A1. BCS70 Sample size across waves

\begin{tabular}{llll}
\hline Wave & Year & Age & N \\
\hline \hline Wave 1 & 1970 & 0 & 17,196 \\
Wave 2 & 1975 & 5 & 13,135 \\
Wave 3 & 1980 & 10 & 14,875 \\
Wave 4 & 1986 & 16 & 11,622 \\
Wave 5 & 1996 & 26 & 9,003 \\
Wave 6 & $1999-2000$ & 30 & 11,261 \\
Wave 7 & $2004-2005$ & 34 & 9,665 \\
Wave 8 & $2008-2009$ & 38 & 8,874 \\
Wave 9 & $2012-2013$ & 42 & 9,841 \\
Wave 10 & 2016 & 46 & N/A \\
Wave 11 & 2020 & 50 & N/A \\
\hline
\end{tabular}




\section{Appendix B: Variable construction and descriptive statistics}

\section{Construction of the variable of social origins}

The construction of our measure of parental class involved using the UK SOC2000 occupational codes of fathers' and mothers' occupation supplied by Tim Morris as part of the ESRC project 'An examination of the impact of family socio-economic status on outcomes in late childhood and adolescence' (ESRC grant: RES-060-23-0011) led by Paul Gregg. Information is used from wave 3 of the survey (1980) when respondents were 10 years old. Combining these occupational codes with information on employment status, we allocated both parents to one of the original seven categories of the National Statistics Socio-Economic Classification (NSSEC), using the reduced method (ONS, 2005). The dominance method (Erikson, 1984) was then used to construct the parental class measure. Following the approach adopted by Authors, 'husband's class is taken to dominate wife's class unless the latter is higher in the ordering of the classes as $1,2,3-5,6,7$, in which case wife's class dominates'. We then collapse the parental class measure into three categories: the salariat (NS-SEC 1-2), the intermediate classes (including the self-employed) (NS-SEC 3-5) and the working classes (NS-SEC 6-7).

As with parental class, for parental status we use information from wave 3 of the BCS70 (1980). We base our parental status measure on the Chan-Goldthorpe (2004) status order. Parents are coded to the 31 categories of the Chan-Goldthorpe status scale which is based on the occupational structure of close friendship. We combine information from both parents using the dominance approach (Erikson, 2984), and from these scores we then derive parental education tertiles.

For parental education, we, again, use data from wave 3 of the BCS70. Information on highest educational attainment is given for both mothers and fathers in the form of five category variables ranging from 1 - having no qualifications - to 5 - having degree-level qualifications. Then, following Authors, these measures were combined to derive a parental education measure taking on the following categories: (1) neither parent has any qualification; (2) one parent has secondary or lower qualification, other parent has no qualification; (3) both parents have secondary or lower qualification; (4) one parent has higher secondary or lower tertiary qualification; (6) one parent has degree-level qualification, other parent has lower qualification; (7) both parents have degree-level qualifications. This method requires a plausible assumption to be made regarding missing values if educational information is only available for one parent. It was assumed that the value of the missing parent equals the model value for partners corresponding to the valid category. Finally, we derived a measure approximating tertiles.

The parental class, parental status and parental education measures were combined according to the rules set out in Table B1. 
Table B1. Construction of the combined measure of social origins

\begin{tabular}{|c|c|c|c|}
\hline \multirow{2}{*}{$\begin{array}{l}\text { Combined measure } \\
\text { of social origins }\end{array}$} & \multicolumn{3}{|c|}{ Components of social origins } \\
\hline & Parental class & Parental status & Parental education \\
\hline \multirow{4}{*}{ Consistently advantaged } & Class $1 / 2$ & Tertile 1 & Tertile 1 \\
\hline & Class $1 / 2$ & Tertile 2 & Tertile 1 \\
\hline & Class $1 / 2$ & Tertile 1 & Tertile 2 \\
\hline & Class $3 / 4 / 5$ & Tertile 1 & Tertile 1 \\
\hline Intermediate & \multicolumn{3}{|c|}{ All other combinations of the three components of social origins } \\
\hline \multirow{4}{*}{ Consistently disadvantaged } & Class $6 / 7$ & Tertile 3 & Tertile 3 \\
\hline & Class $6 / 7$ & Tertile 2 & Tertile 3 \\
\hline & Class $6 / 7$ & Tertile 3 & Tertile 2 \\
\hline & Class $3 / 4 / 5$ & Tertile 3 & Tertile 3 \\
\hline
\end{tabular}

Notes: Tertile 1: top tertile, Tertile 2: middle tertile, Tertile 3: bottom tertile.

\section{Construction of the variable of cognitive ability}

In BCS70, cognitive ability was measured via scores attained on four subtests of the British Ability Scales (BAS), administered when respondents were aged 10. These subtests (with number of items and their original variable names) were: Word Definitions (37 items, i3504i3540) and Word Similarities (42 items, i35475-i3616) to measure verbal ability, and Recall of Digits (34 items, i3541-i3574) and Matricies (28 items, i3617-i3644) to measure non-verbal ability.

We seek to capture the notion of 'general intelligence' - often referred to as ' $g$ ' (Spearman, 1904; Deary, 2001). This relies on capturing the common variance across ability tests, and is an approach which has commonly been employed in previous studies using BCS70 (e.g. Schoon, $2008,2010)$. We are aware of the distinctions that have been made between 'fluid' and 'crystallized' intelligence (Cattel, 1971). The former is typically captured via tests of numerical ability while the latter is often captured via tests of reading, vocabulary, and so on. With the non-verbal and verbal components of the BAS subtests, we see our measure of cognitive ability as capturing both types of intelligences. The view that has commonly been expressed by psychometric researchers is that there is usually little reason to isolate these types of intelligences and, if one does, this would not necessarily successfully capture ' $g$ ' (Marks, 2014; Jensen 1998).

Following the approach employed by Schoon (2008, 2010), a principal component analysis (PCA) was carried out on the BAS subtests specified above. Scores were saved from the first unrotated component extracted and this was taken to represent cognitive ability. Table B2 gives the results of the PCA and a summary of the variable in its final continuous form; Figure B1 gives the percentile distribution of the measure (i.e., before we derived tertiles, which we use for analysis). 
Table B2. Results of principal component analysis for cognitive ability

\begin{tabular}{|c|c|c|c|c|c|c|c|c|}
\hline \multicolumn{6}{|c|}{ PCA } & \multicolumn{3}{|c|}{ New measure } \\
\hline $\begin{array}{c}\text { Eigenvalu } \\
\mathrm{e}\end{array}$ & Loading & & & & $\begin{array}{c}\text { Variance } \\
\text { explaine } \\
\text { d }\end{array}$ & Min & Max & $\begin{array}{c}\text { Mean } \\
\text { (SD) }\end{array}$ \\
\hline & $\begin{array}{c}\text { Word } \\
\text { definition } \\
\mathrm{s}\end{array}$ & $\begin{array}{c}\text { Word } \\
\text { similaritie } \\
\mathrm{s}\end{array}$ & Recall & $\begin{array}{c}\text { Matrice } \\
\mathrm{s}\end{array}$ & & & & \\
\hline 2.31 & 0.55 & 0.55 & 0.39 & 0.49 & 0.58 & -5.64 & 5.13 & $\begin{array}{c}0.00 \\
(1.52)\end{array}$ \\
\hline
\end{tabular}

Figure B1. Distribution of cognitive ability

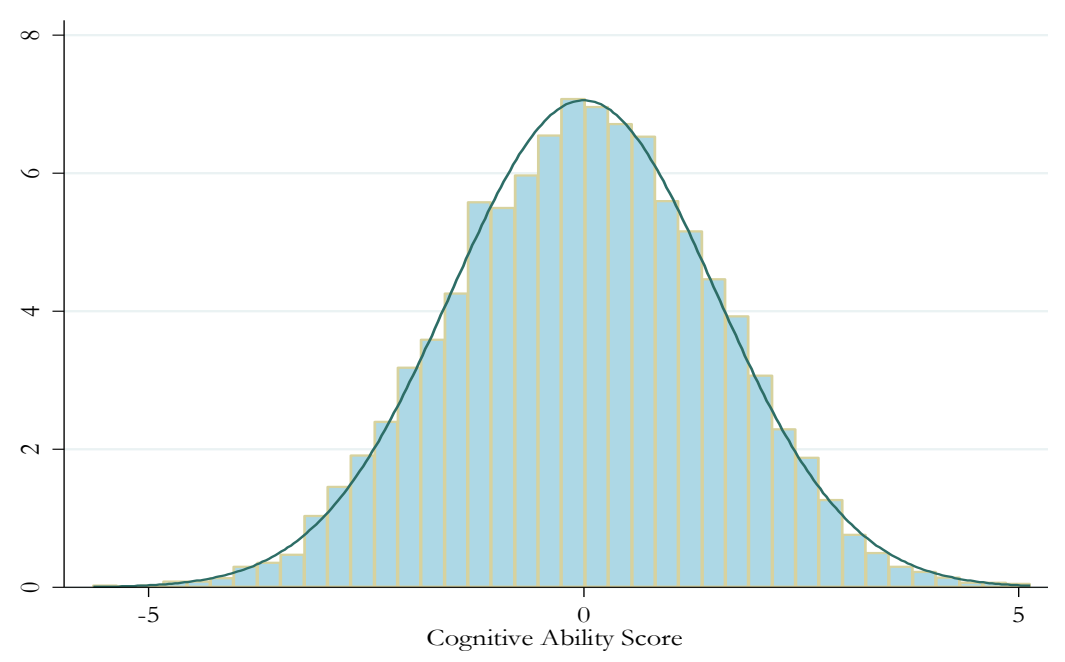

Descriptive statistics

Table B3. Descriptive statistics for all variables in our analyses

$\%$ or Mean

Level of academic qualification (\%)

No qualifications

$32.8 \%$

Below O-level or GCSE

$11.5 \%$

1-4 O-level or GCSE passes

$13.7 \%$

$5+$ O-level or GCSE passes or 1 A-level pass

$18.7 \%$

2+ A-level passes

$5.0 \%$

Tertiary sub-degree qualification

$6.2 \%$

Degree

$10.3 \%$

Masters degree, PhD

$1.9 \%$

Total

$100.0 \%$ 
Level of vocational qualification (\%)

No qualifications

$53.6 \%$

NVQ1

$8.4 \%$

NVQ2

$19.7 \%$

NVQ3

$10.9 \%$

NVQ4

$6.0 \%$

NVQ5-6

$1.3 \%$

Total

$100.0 \%$

Research question 1, dependent variables: mean levels of educational qualification Average level of academic qualification at age 16

Average level of academic qualification at age 38

Average level of vocational qualification at age 16

Average level of vocational qualification score at age 38

Research question 2, dependent variable: social class at age 38 (\%)

Salariat (NS-SEC 1-2)

$38.3 \%$

Intermediate (NS-SEC 3 and 5)

$22.5 \%$

Self-employed (NS-SEC 4)

$10.4 \%$

Working class (NS-SEC 6-7)

$28.8 \%$

Total

$100.0 \%$

Social origins (\%)

Consistently advantaged

$23.3 \%$

Intermediate

$53.0 \%$

Consistently disadvantaged

$23.7 \%$

Total

$100.0 \%$

Cognitive ability tertiles (\%)

High ability

Middle

Low ability

Total $100.0 \%$

Combination of social origin and cognitive ability (\%)

Consistently disadvantaged, high ability

Consistently disadvantaged, middle ability

Consistently disadvantaged, low ability

$12.2 \%$

Intermediate, high ability

$16.4 \%$

Intermediate, middle ability

$18.9 \%$

Intermediate, low ability

$17.7 \%$

Consistently advantaged, high ability

$13.0 \%$

Consistently advantaged, middle ability

$6.8 \%$

Consistently advantaged, low ability

$3.5 \%$

Total

$100.0 \%$ 
Respondent improved on the level of their academic qualifications by age 38 (dummy) (\%)

Yes

$17.7 \%$

No

$82.3 \%$

Total

$100.0 \%$

Respondent improved on the level of their vocational qualifications by age 38 (dummy) (\%)

Yes

$29.9 \%$

No

$70.1 \%$

Total

$100.0 \%$

Initial level of qualification (attainment upon leaving FT education) (\%)

No qualifications

Below O-level, NVQ 1

$11.1 \%$

1-4 O-level passes, NVQ 2

$16.1 \%$

5+ O-level passes or 1 A-level pass, NVQ 3

$19.8 \%$

$2+$ A-level passes

$5.0 \%$

Tertiary level sub-degree qualification, NVQ 4

$4.1 \%$

Tertiary level degree qualification, NVQ 5

$10.7 \%$

Tertiary level higher degree, NVQ 6

$1.2 \%$

Total

$100.0 \%$

Respondent's own class distribution: age 37 (\%)

Higher managerial and professional

$14.7 \%$

Lower managerial and professional

$23.2 \%$

Intermediate

$19.2 \%$

Small employers and own account workers

$9.7 \%$

Lower supervisory and technical

$5.0 \%$

Semi routine

$17.1 \%$

Routine

$10.3 \%$

Never worked

$0.8 \%$

Total

$100.0 \%$

Gender (\%)

Male

$49.3 \%$

Female

$50.7 \%$

Total

$100.0 \%$ 


\section{Appendix C: Multiple imputation}

We consider multiple imputation to be a necessary exercise to limit variations in sample selection and bias, as far as possible. Table B1 highlights the extent of missingness on our key variables. We gave much consideration to the specification of our imputation models. MI relies on the missing at random (MAR) assumption, which cannot be directly tested but, for reasons given in Kuha (2013), we see it as plausible in the case of BCS70 data. Our imputation models included all the variables that entered the analyses models, as well as relevant auxiliary variables. Examples of such auxiliary variables included parents' prior class and educational attainment, and scores gained by respondents in alternative tests of $I Q$ and academic competence. The inclusion of auxiliary variables has in the past been shown to make the MAR assumption more plausible and improve the accuracy of imputed values (von Hippel and Lynch, 2013).

Regression-based imputation also relies on the standard assumption of the independence of observations. Since we use repeated measures data for research question 1 , this assumption is violated. We carry out the imputation with the data in wide form (Allison, 2001), so that correlations between the various time points is explicitly taken into account and we can exploit information from one time point that can be an important predictor of missing information for the same individual at another.

Table C1. Missingness on key variables

\begin{tabular}{lcc}
\hline & $\mathrm{N}$ & $\%$ \\
\hline Original sample N=18737 & & \\
& & \\
Educational and occupational histories & 6600 & 35.22 \\
Combined social origins & 1698 & 9.06 \\
Cognitive ability & 3338 & 17.82 \\
Gender & 0 & 0.00 \\
Initial education & 0 & 0.00 \\
Academic further qualification dummy & 0 & 0.00 \\
Vocational further qualification dummy & 0 & 0.00 \\
Individuals' own social class: Missing >=1 year & 7849 & 41.89 \\
Individuals' own social class: Missing every year & 83 & 0.44 \\
Individuals' own social class: Missing at age 38 & 3456 & 18.44 \\
\hline
\end{tabular}




\section{Appendix D: Results from auxiliary analyses}

TABLE D1: Effects of individual characteristics on accumulation of academic qualifications between leaving full-time education and age 38 - results from growth curve models

\begin{tabular}{|c|c|c|c|c|c|c|c|c|c|c|c|c|c|c|c|c|c|c|c|c|}
\hline & \multicolumn{2}{|c|}{ M0 } & \multicolumn{2}{|c|}{ M1 } & \multicolumn{2}{|c|}{ M2 } & \multicolumn{2}{|c|}{ M3 } & \multicolumn{2}{|c|}{ M4 } & \multicolumn{2}{|c|}{ M5 } & \multicolumn{2}{|c|}{ M6 } & \multicolumn{2}{|c|}{ M7 } & \multicolumn{2}{|c|}{ M8 } & \multicolumn{2}{|c|}{ M9 } \\
\hline & $\mathrm{B}$ & SE & $\mathrm{B}$ & SE & $\mathrm{B}$ & SE & $\mathrm{B}$ & SE & $\mathrm{B}$ & SE & $\mathrm{B}$ & $\mathrm{SE}$ & $\mathrm{B}$ & SE & $\mathrm{B}$ & SE & $\mathrm{B}$ & SE & $\mathrm{B}$ & SE \\
\hline \multicolumn{21}{|l|}{$\begin{array}{l}\text { FIXED PART } \\
\end{array}$} \\
\hline \multicolumn{21}{|l|}{ Cognitive ability (ref.: high) } \\
\hline Low & & & & & & & -0.142 & 0.021 & 0.855 & 0.046 & -0.142 & 0.021 & 0.670 & 0.048 & -0.126 & 0.038 & 0.687 & 0.058 & 0.450 & 0.096 \\
\hline Middle & & & & & & & -0.078 & 0.020 & 0.544 & 0.045 & -0.078 & 0.020 & 0.433 & 0.045 & -0.068 & 0.041 & 0.445 & 0.055 & 0.267 & 0.098 \\
\hline \multicolumn{21}{|l|}{ Social origins (ref.: consistently disadvantaged) } \\
\hline Intermediate & & & & & & & 0.006 & 0.016 & 0.006 & 0.016 & -0.318 & 0.040 & -0.191 & 0.040 & 0.028 & 0.038 & -0.167 & 0.053 & -0.336 & 0.094 \\
\hline Consistently advantaged & & & & & & & 0.096 & 0.020 & 0.096 & 0.020 & -0.894 & 0.046 & -0.587 & 0.048 & 0.097 & 0.040 & -0.584 & 0.059 & -0.830 & 0.094 \\
\hline \multicolumn{21}{|l|}{ Cognitive ability* Age } \\
\hline Low*Age & & & & & & & & & -0.052 & 0.002 & & & -0.042 & 0.002 & & & -0.042 & 0.002 & -0.030 & 0.005 \\
\hline Middle*Age & & & & & & & & & -0.032 & 0.002 & & & -0.027 & 0.002 & & & -0.027 & 0.002 & -0.017 & 0.005 \\
\hline \multicolumn{21}{|l|}{ Social origins* Age } \\
\hline Intermediate*Age & & & & & & & & & & & 0.017 & 0.002 & 0.010 & 0.002 & & & 0.010 & 0.002 & 0.019 & 0.004 \\
\hline Consistently advantaged $*$ Age & & & & & & & & & & & 0.052 & 0.002 & 0.036 & 0.002 & & & 0.036 & 0.002 & 0.048 & 0.005 \\
\hline \multicolumn{21}{|l|}{ Social origins* Cognitive ability } \\
\hline Intermediate*Low & & & & & & & & & & & & & & & -0.031 & 0.044 & -0.033 & 0.044 & 0.197 & 0.113 \\
\hline Intermediate*Middle & & & & & & & & & & & & & & & -0.025 & 0.049 & -0.027 & 0.049 & 0.130 & 0.118 \\
\hline Consistently advantaged*Low & & & & & & & & & & & & & & & 0.003 & 0.056 & 0.001 & 0.056 & 0.489 & 0.134 \\
\hline Consistently advantaged*Middle & & & & & & & & & & & & & & & 0.014 & 0.057 & 0.013 & 0.057 & 0.290 & 0.127 \\
\hline \multicolumn{21}{|l|}{ Origin * Ability * Age } \\
\hline Intermediate $*$ Low $*$ Age & & & & & & & & & & & & & & & & & & & -0.012 & 0.008 \\
\hline Intermediate $*$ Middle $*$ Age & & & & & & & & & & & & & & & & & & & -0.008 & 0.006 \\
\hline Consistently advantaged $*$ Low $*$ Age & & & & & & & & & & & & & & & & & & & -0.025 & 0.006 \\
\hline Consistently advantaged $*$ Middle $*$ Age & & & & & & & & & & & & & & & & & & & -0.014 & 0.006 \\
\hline Age & 0.049 & 0.000 & 0.049 & 0.001 & 0.040 & 0.001 & 0.040 & 0.001 & 0.068 & 0.001 & 0.019 & 0.002 & 0.049 & 0.002 & 0.040 & 0.001 & 0.049 & 0.002 & 0.040 & 0.004 \\
\hline
\end{tabular}


Initial education (ref: lower secondary-high perf.)

\section{No qualifications}

Sub-secondary

Lower secondary-low performance

Higher secondary

Lower tertiary

Higher tertiary

Post-graduate

Social class - lagged (ref.: Class 4)

Never worked

Class 7

Class 6

Class 5

Class 3

Class 2

Class 1

Gender

Female

Constant

\section{RANDOM PART}

Between-individual variance

Within-individual variance

Total variance

Slope variance

Intercept-slope correlation

Variance partition

Individual

Life-course

N observation

N groups

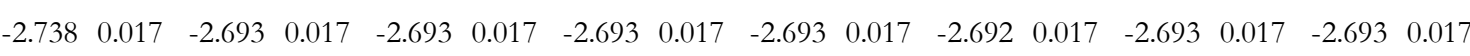
$\begin{array}{llllllllllllllll}-1.822 & 0.022 & -1.771 & 0.023 & -1.772 & 0.023 & -1.771 & 0.023 & -1.772 & 0.023 & -1.771 & 0.023 & -1.772 & 0.023 & -1.771 & 0.023\end{array}$

$\begin{array}{lllllllllllllllll}-1.109 & 0.020 & -1.081 & 0.020 & -1.082 & 0.020 & -1.082 & 0.020 & -1.082 & 0.020 & -1.081 & 0.020 & -1.082 & 0.020 & -1.082 & 0.020\end{array}$ $\begin{array}{llllllllllllllll}0.921 & 0.029 & 0.885 & 0.029 & 0.886 & 0.029 & 0.885 & 0.029 & 0.886 & 0.029 & 0.886 & 0.030 & 0.886 & 0.030 & 0.886 & 0.030\end{array}$ $\begin{array}{llllllllllllllll}0.730 & 0.032 & 0.727 & 0.032 & 0.727 & 0.032 & 0.727 & 0.032 & 0.727 & 0.032 & 0.727 & 0.032 & 0.728 & 0.032 & 0.728 & 0.032\end{array}$ $\begin{array}{llllllllllllllll}1.275 & 0.023 & 1.228 & 0.023 & 1.229 & 0.023 & 1.228 & 0.023 & 1.229 & 0.023 & 1.230 & 0.023 & 1.231 & 0.024 & 1.231 & 0.024\end{array}$ $\begin{array}{llllllllllllllll}1.353 & 0.057 & 1.302 & 0.057 & 1.304 & 0.057 & 1.302 & 0.057 & 1.304 & 0.057 & 1.306 & 0.057 & 1.307 & 0.057 & 1.307 & 0.057\end{array}$

$\begin{array}{llllllllllllllll}-0.370 & 0.013 & -0.370 & 0.013 & -0.370 & 0.013 & -0.369 & 0.013 & -0.370 & 0.013 & -0.370 & 0.013 & -0.370 & 0.013 & -0.370 & 0.013\end{array}$ $\begin{array}{llllllllllllllll}-0.051 & 0.009 & -0.051 & 0.009 & -0.051 & 0.009 & -0.050 & 0.009 & -0.051 & 0.009 & -0.051 & 0.009 & -0.051 & 0.009 & -0.051 & 0.009\end{array}$ $\begin{array}{llllllllllllllll}-0.009 & 0.008 & -0.009 & 0.008 & -0.009 & 0.008 & -0.009 & 0.008 & -0.009 & 0.008 & -0.009 & 0.008 & -0.009 & 0.008 & -0.009 & 0.008\end{array}$ $\begin{array}{llllllllllllllll}-0.041 & 0.009 & -0.041 & 0.009 & -0.041 & 0.009 & -0.040 & 0.009 & -0.040 & 0.009 & -0.041 & 0.009 & -0.040 & 0.009 & -0.040 & 0.009\end{array}$ $\begin{array}{llllllllllllllll}0.093 & 0.008 & 0.093 & 0.008 & 0.093 & 0.008 & 0.093 & 0.008 & 0.093 & 0.008 & 0.093 & 0.008 & 0.093 & 0.008 & 0.093 & 0.008\end{array}$ $\begin{array}{llllllllllllllll}0.163 & 0.008 & 0.163 & 0.008 & 0.161 & 0.008 & 0.162 & 0.008 & 0.160 & 0.008 & 0.163 & 0.008 & 0.160 & 0.008 & 0.160 & 0.008\end{array}$ $\begin{array}{llllllllllllllll}0.249 & 0.009 & 0.249 & 0.009 & 0.244 & 0.009 & 0.246 & 0.009 & 0.243 & 0.009 & 0.249 & 0.009 & 0.243 & 0.009 & 0.243 & 0.009\end{array}$

$\begin{array}{llllllllllllllll}-0.014 & 0.012 & -0.006 & 0.012 & -0.007 & 0.012 & -0.007 & 0.012 & -0.007 & 0.012 & -0.006 & 0.012 & -0.007 & 0.012 & -0.007 & 0.012\end{array}$

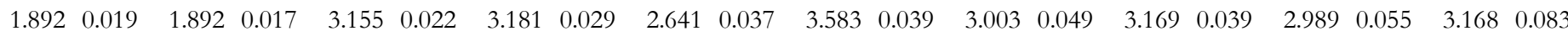

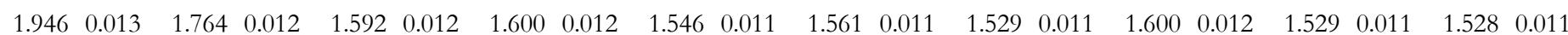
$\begin{array}{llllllllllllllllllll}0.753 & 0.001 & 0.517 & 0.001 & 0.508 & 0.001 & 0.508 & 0.001 & 0.508 & 0.001 & 0.508 & 0.001 & 0.508 & 0.001 & 0.508 & 0.001 & 0.508 & 0.001 & 0.508 & 0.001\end{array}$ $\begin{array}{llllllllll}2.699 & 2.281 & 2.100 & 2.108 & 2.054 & 2.069 & 2.037 & 2.108 & 2.037 & 2.036\end{array}$ $\begin{array}{llllllllllllllllll}0.081 & 0.001 & 0.079 & 0.001 & 0.079 & 0.001 & 0.076 & 0.001 & 0.076 & 0.001 & 0.075 & 0.001 & 0.079 & 0.001 & 0.075 & 0.001 & 0.074 & 0.001\end{array}$ $\begin{array}{llllllllllllllllllll}-0.528 & 0.007 & -0.921 & 0.001 & -0.923 & 0.001 & -0.917 & 0.002 & -0.919 & 0.002 & -0.915 & 0.002 & -0.923 & 0.001 & -0.915 & 0.002 & -0.915 & 0.002\end{array}$

$28 \%$

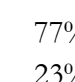

$23 \%$

\begin{abstract}
$76 \%$
\end{abstract}
$24 \%$

\begin{abstract}
$76 \%$
\end{abstract}
$75 \%$

$25 \%$

\begin{abstract}
$75 \%$
\end{abstract}
$25 \%$

\section{$75 \%$}

$25 \%$

279151 
TABLE D2: Effects of individual characteristics on accumulation of vocational qualifications between leaving full-time education and age 38 - results from growth curve models

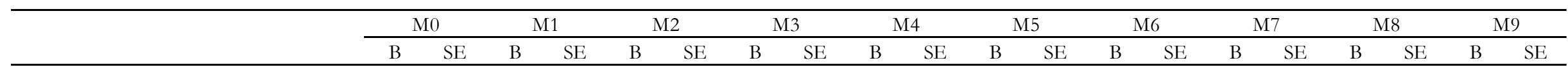

\section{FIXED PART}

Cognitive ability (ref.: high)

Low

Middle

$0.103 \quad 0.023$

0.0950 .022

$0.350 \quad 0.038$

0.1720 .037

$0.103 \quad 0.023$

$\begin{array}{llll}0.338 & 0.040 & -0.021 & 0.049\end{array}$

$\begin{array}{llll}0.214 & 0.058 & 0.344 & 0.082\end{array}$

Social origins (ref.: consistently disadvantaged)

Intermediate

Consistently advantaged

$\begin{array}{llllllllllllll}0.053 & 0.020 & 0.053 & 0.020 & -0.018 & 0.034 & 0.021 & 0.034 & -0.045 & 0.047 & -0.076 & 0.053 & 0.016 & 0.078\end{array}$ $\begin{array}{llllllllllllll}0.004 & 0.027 & 0.004 & 0.027 & -0.130 & 0.041 & -0.044 & 0.043 & -0.122 & 0.048 & -0.169 & 0.059 & -0.031 & 0.080\end{array}$

Cognitive ability* Age

Low*Age

Middle*Age

$\begin{array}{llll}-0.015 & 0.002 & -0.014 & 0.002\end{array}$

$\begin{array}{llll}-0.005 & 0.002 & -0.004 & 0.002\end{array}$

$\begin{array}{llll}0.004 & 0.002 & 0.002 & 0.002\end{array}$

$\begin{array}{lllll}0.008 & 0.002 & 0.003 & 0.002\end{array}$

Intermediate*Age

Consistently advantaged*Age

Social origins ${ }^{*}$ Cognitive ability

Intermediate*Low

Intermediate*Middle

Consistently advantaged*Low

Consistently advantaged*Middle

Origin * Ability * Age

Intermediate $*$ Low $*$ Age

Intermediate $*$ Middle $*$ Age

Consistently advantaged $*$ Low $*$ Age

Consistently advantaged $*$ Middle $*$ Age $\begin{array}{llll}0.002 & 0.002 & -0.003 & 0.004\end{array}$

$\begin{array}{lllll}0.003 & 0.002 & -0.005 & 0.004\end{array}$

$\begin{array}{llllll}0.140 & 0.059 & 0.139 & 0.059 & -0.001 & 0.098\end{array}$

$\begin{array}{lllllll}0.089 & 0.060 & 0.088 & 0.060 & 0.017 & 0.100\end{array}$

$\begin{array}{llllll}0.195 & 0.073 & 0.194 & 0.072 & 0.001 & 0.124\end{array}$

$\begin{array}{lllllll}0.157 & 0.067 & 0.157 & 0.066 & -0.044 & 0.108\end{array}$

$0.008 \quad 0.005$

$0.004 \quad 0.005$

$0.011 \quad 0.005$

0.0120 .005

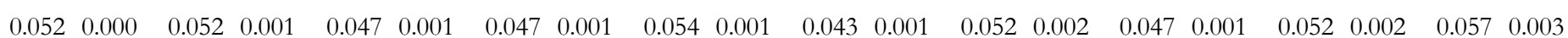


Initial education (ref: lower secondary-high perf.)

\section{No qualifications}

Sub-secondary

Lower secondary-low performance

Higher secondary

Lower tertiary

Higher tertiary

Post-graduate

Social class - lagged (ref.: Class 4)

Never worked

Class 7

Class 6

Class 5

Class 3

Class 2

Class 1

Gender

Female

Constant

\section{RANDOM PART}

Between-individual variance

Within-individual variance

Total variance

Slope variance

Intercept-slope correlation

Variance partition

Individual

Life-course

N observation

N groups $\begin{array}{llllllllllllllll}-0.474 & 0.022 & -0.494 & 0.023 & -0.495 & 0.023 & -0.494 & 0.023 & -0.495 & 0.023 & -0.493 & 0.023 & -0.493 & 0.023 & -0.493 & 0.023\end{array}$ $\begin{array}{llllllllllllllll}-0.251 & 0.029 & -0.276 & 0.029 & -0.276 & 0.029 & -0.276 & 0.029 & -0.276 & 0.029 & -0.275 & 0.029 & -0.276 & 0.029 & -0.276 & 0.029\end{array}$ $\begin{array}{lllllllllllllllll}0.121 & 0.026 & 0.106 & 0.026 & 0.106 & 0.026 & 0.106 & 0.026 & 0.106 & 0.026 & 0.105 & 0.026 & 0.104 & 0.026 & 0.104 & 0.026\end{array}$ $\begin{array}{llllllllllllllll}-0.605 & 0.038 & -0.579 & 0.039 & -0.579 & 0.039 & -0.579 & 0.039 & -0.579 & 0.039 & -0.574 & 0.039 & -0.574 & 0.039 & -0.574 & 0.039\end{array}$ $\begin{array}{llllllllllllllll}0.525 & 0.042 & 0.529 & 0.042 & 0.529 & 0.042 & 0.529 & 0.042 & 0.529 & 0.042 & 0.531 & 0.042 & 0.531 & 0.042 & 0.531 & 0.042\end{array}$ $\begin{array}{llllllllllllllll}-0.614 & 0.029 & -0.575 & 0.030 & -0.575 & 0.030 & -0.575 & 0.030 & -0.575 & 0.030 & -0.565 & 0.030 & -0.565 & 0.030 & -0.565 & 0.030\end{array}$ $\begin{array}{llllllllllllllll}-0.772 & 0.074 & -0.725 & 0.074 & -0.724 & 0.074 & -0.725 & 0.074 & -0.724 & 0.074 & -0.711 & 0.074 & -0.711 & 0.074 & -0.711 & 0.074\end{array}$

$\begin{array}{llllllllllllllll}-0.317 & 0.012 & -0.317 & 0.012 & -0.318 & 0.012 & -0.317 & 0.012 & -0.318 & 0.012 & -0.317 & 0.012 & -0.318 & 0.012 & -0.318 & 0.012\end{array}$ $\begin{array}{llllllllllllllll}-0.055 & 0.009 & -0.055 & 0.009 & -0.055 & 0.009 & -0.055 & 0.009 & -0.055 & 0.009 & -0.055 & 0.009 & -0.055 & 0.009 & -0.055 & 0.009\end{array}$ $\begin{array}{llllllllllllllll}-0.047 & 0.008 & -0.047 & 0.008 & -0.047 & 0.008 & -0.047 & 0.008 & -0.047 & 0.008 & -0.047 & 0.008 & -0.047 & 0.008 & -0.047 & 0.008\end{array}$ $\begin{array}{llllllllllllllll}0.041 & 0.010 & 0.041 & 0.010 & 0.041 & 0.010 & 0.041 & 0.010 & 0.041 & 0.010 & 0.041 & 0.010 & 0.041 & 0.010 & 0.041 & 0.010\end{array}$ $\begin{array}{llllllllllllllll}0.015 & 0.008 & 0.016 & 0.008 & 0.016 & 0.008 & 0.016 & 0.008 & 0.016 & 0.008 & 0.016 & 0.008 & 0.016 & 0.008 & 0.016 & 0.008\end{array}$ $\begin{array}{llllllllllllllll}0.053 & 0.009 & 0.053 & 0.009 & 0.053 & 0.009 & 0.053 & 0.009 & 0.053 & 0.009 & 0.053 & 0.009 & 0.053 & 0.009 & 0.053 & 0.009\end{array}$ $\begin{array}{llllllllllllllll}0.012 & 0.010 & 0.012 & 0.010 & 0.010 & 0.010 & 0.011 & 0.010 & 0.010 & 0.010 & 0.012 & 0.010 & 0.010 & 0.010 & 0.010 & 0.010\end{array}$

$\begin{array}{llllllllllllllll}-0.086 & 0.015 & -0.091 & 0.015 & -0.091 & 0.015 & -0.091 & 0.015 & -0.091 & 0.015 & -0.091 & 0.015 & -0.092 & 0.015 & -0.092 & 0.015\end{array}$

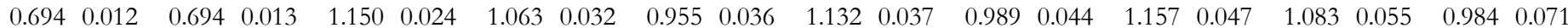

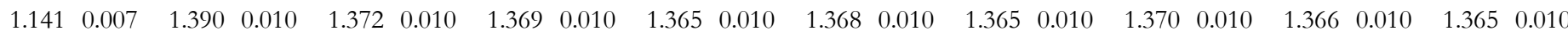
$\begin{array}{lllllllllllllllllllllll}0.695 & 0.001 & 0.525 & 0.001 & 0.521 & 0.001 & 0.521 & 0.001 & 0.521 & 0.001 & 0.521 & 0.001 & 0.521 & 0.001 & 0.521 & 0.001 & 0.521 & 0.001 & 0.521 & 0.001\end{array}$ $\begin{array}{llllllllll}1.836 & 1.915 & 1.893 & 1.890 & 1.886 & 1.889 & 1.886 & 1.891 & 1.887 & 1.886\end{array}$ $\begin{array}{llllllllllllllllll}0.067 & 0.000 & 0.067 & 0.000 & 0.067 & 0.000 & 0.067 & 0.000 & 0.067 & 0.000 & 0.067 & 0.000 & 0.067 & 0.000 & 0.067 & 0.000 & 0.067 & 0.000\end{array}$ $\begin{array}{llllllllllllllllllllll}-0.775 & 0.004 & -0.803 & 0.003 & -0.803 & 0.003 & -0.802 & 0.003 & -0.803 & 0.003 & -0.802 & 0.003 & -0.804 & 0.003 & -0.802 & 0.003 & -0.802 & 0.003\end{array}$
$72 \%$

$28 \%$
$28 \%$
$72 \%$

$28 \%$

\begin{abstract}
$72 \%$
\end{abstract}
$28 \%$

\section{$72 \%$}

$28 \%$
$72 \%$

$28 \%$
$72 \%$ $28 \%$

279151 
TABLE D3: Robustness check for curvilinear effects of age - three selected models

\begin{tabular}{|c|c|c|c|c|c|c|c|c|c|c|c|c|}
\hline & \multicolumn{6}{|c|}{ Academic qualifications } & \multicolumn{6}{|c|}{ Vocational qualifications } \\
\hline & \multicolumn{2}{|c|}{ M0 } & \multicolumn{2}{|c|}{ M1 } & \multicolumn{2}{|c|}{ M3 } & \multicolumn{2}{|c|}{ M0 } & \multicolumn{2}{|c|}{ M1 } & \multicolumn{2}{|c|}{ M3 } \\
\hline & $\mathrm{B}$ & SE & $\mathrm{B}$ & SE & $\mathrm{B}$ & SE & $\mathrm{B}$ & SE & $\mathrm{B}$ & SE & $\mathrm{B}$ & SE \\
\hline \multicolumn{13}{|l|}{ FIXED PART } \\
\hline \multicolumn{13}{|l|}{ Cognitive ability (ref.: high) } \\
\hline Low & & & & & -0.151 & 0.020 & & & & & 0.092 & 0.023 \\
\hline Middle & & & & & -0.079 & 0.019 & & & & & 0.093 & 0.021 \\
\hline \multicolumn{13}{|c|}{ Social origins (ref.: consistently disadvantaged) } \\
\hline Intermediate & & & & & 0.012 & 0.015 & & & & & 0.060 & 0.020 \\
\hline Consistently advantaged & & & & & 0.103 & 0.019 & & & & & 0.012 & 0.027 \\
\hline Age & 0.222 & 0.002 & 0.222 & 0.002 & 0.190 & 0.002 & 0.222 & 0.002 & 0.222 & 0.001 & 0.211 & 0.002 \\
\hline $\operatorname{Age}^{2}$ & -0.003 & 0.004 & -0.003 & 0.002 & -0.003 & 0.004 & -0.003 & 0.003 & -0.003 & 0.002 & -0.003 & 0.003 \\
\hline Constant & -0.306 & 0.031 & -0.306 & 0.023 & 1.222 & 0.041 & -1.462 & 0.025 & -1.462 & 0.021 & -1.064 & 0.039 \\
\hline \multicolumn{13}{|l|}{ RANDOM PART } \\
\hline Between-individual variance & 1.946 & 0.013 & 1.767 & 0.012 & 1.603 & 0.012 & 1.141 & 0.013 & 1.394 & 0.010 & 1.367 & 0.010 \\
\hline Within-individual variance & 0.742 & 0.001 & 0.500 & 0.001 & 0.497 & 0.001 & 0.683 & 0.001 & 0.509 & 0.001 & 0.509 & 0.001 \\
\hline Total variance & 2.688 & & 2.268 & & 2.101 & & 1.825 & & 1.903 & & 1.876 & \\
\hline Slope variance & & & 0.081 & 0.001 & 0.081 & 0.001 & & & 0.067 & 0.000 & 0.067 & 0.000 \\
\hline Intercept-slope correlation & & & -0.529 & 0.007 & -0.923 & 0.001 & & & -0.776 & 0.004 & -0.803 & 0.003 \\
\hline \multicolumn{13}{|l|}{ V ariance partition } \\
\hline Individual & $72 \%$ & & $78 \%$ & & $76 \%$ & & $63 \%$ & & $73 \%$ & & $73 \%$ & \\
\hline Life-course & $28 \%$ & & $22 \%$ & & $24 \%$ & & $37 \%$ & & $27 \%$ & & $27 \%$ & \\
\hline
\end{tabular}

Note:

Controls are included. 
Table D4: Effects of all explanatory variables and controls on the probability of being found in different class positions at age 38 (AMEs, \%)

\begin{tabular}{|c|c|c|c|c|c|c|c|c|c|c|c|c|c|c|c|c|}
\hline & \multicolumn{8}{|c|}{ Mo } & \multicolumn{8}{|c|}{ M1 } \\
\hline & \multicolumn{2}{|c|}{ Working class } & \multicolumn{2}{|c|}{ Intermediate } & \multicolumn{2}{|c|}{ Small employers } & \multicolumn{2}{|c|}{ Salariat } & \multicolumn{2}{|c|}{ Working class } & \multicolumn{2}{|c|}{ Intermediate } & \multicolumn{2}{|c|}{ Small employers } & \multicolumn{2}{|c|}{ Salariat } \\
\hline & AME & SE & AME & SE & $\mathrm{AME}$ & SE & AME & SE & AME & SE & AME & SE & AME & SE & AME & SE \\
\hline \multicolumn{17}{|l|}{ Origins-ability } \\
\hline \multicolumn{17}{|l|}{ Consistently disadvantaged, high ability } \\
\hline Consistently disadvantaged, middle ability & & & & & & & & & 8.415 & 2.796 & 1.308 & 2.893 & 0.115 & 2.176 & -9.839 & 2.960 \\
\hline Consistently disadvantaged, low ability & & & & & & & & & 16.425 & 3.154 & -0.445 & 2.888 & 0.714 & 2.031 & -16.694 & 3.147 \\
\hline Intermediate, high ability & & & & & & & & & -5.878 & 2.697 & 0.237 & 2.799 & -0.347 & 2.075 & 5.988 & 2.583 \\
\hline Intermediate, middle ability & & & & & & & & & -2.368 & 2.597 & 3.588 & 2.573 & 1.111 & 1.959 & -2.331 & 2.696 \\
\hline Intermediate, low ability & & & & & & & & & 8.014 & 2.784 & 0.900 & 2.775 & 2.148 & 2.050 & -11.061 & 2.789 \\
\hline Consistently advantaged, high ability & & & & & & & & & -9.021 & 2.947 & -1.906 & 2.823 & -0.312 & 1.986 & 11.239 & 2.908 \\
\hline Consistently advantaged, middle ability & & & & & & & & & -4.791 & 2.914 & 0.891 & 2.847 & 0.402 & 2.221 & 3.498 & 3.183 \\
\hline Consistently advantaged, low ability & & & & & & & & & 2.016 & 3.419 & -0.889 & 3.493 & 2.496 & 2.522 & -3.623 & 3.682 \\
\hline \multicolumn{17}{|l|}{ Obtained further academic qualifications } \\
\hline \\
\hline \multicolumn{17}{|l|}{ Obtained further vocational qualifications } \\
\hline \multicolumn{17}{|l|}{ Yes } \\
\hline \multicolumn{17}{|l|}{ Initial education (ref: 5+ O-levels) } \\
\hline No qualifications & 23.692 & 1.380 & -5.101 & 1.314 & 2.148 & 0.943 & -20.739 & 1.302 & 17.744 & 1.401 & -4.947 & 1.337 & 1.840 & 0.983 & -14.637 & 1.381 \\
\hline Below O-level, NVQ 1 & 22.425 & 1.740 & -1.841 & 1.648 & 4.184 & 1.315 & -24.768 & 1.641 & 16.089 & 1.766 & -1.582 & 1.708 & 3.881 & 1.368 & -18.388 & 1.839 \\
\hline O-level passes, NVQ2 & 14.447 & 1.550 & 0.765 & 1.432 & 2.224 & 1.106 & -17.436 & 1.623 & 11.302 & 1.580 & 0.305 & 1.448 & 1.854 & 1.142 & -13.461 & 1.603 \\
\hline 2+ A-level passes & -13.335 & 1.374 & -9.607 & 1.912 & -3.367 & 1.264 & 26.309 & 2.310 & -12.626 & 1.739 & -7.227 & 2.115 & -2.472 & 1.433 & 22.325 & 2.507 \\
\hline Tertiary sub-degree qualification, NVQ 4 & -5.922 & 1.833 & -5.994 & 2.250 & 3.607 & 1.806 & 8.309 & 2.640 & -5.583 & 2.045 & -5.590 & 2.295 & 3.976 & 1.882 & 7.197 & 2.598 \\
\hline Degree, NVQ5 or 6 & -14.923 & 1.105 & -16.406 & 1.373 & -4.784 & 0.956 & 36.113 & 1.554 & -14.158 & 1.380 & -14.120 & 1.556 & -3.757 & 1.087 & 32.035 & 1.738 \\
\hline Higher degree & -16.299 & 1.898 & -18.324 & 3.328 & -5.206 & 2.058 & 39.829 & 3.718 & -16.095 & 3.042 & -15.964 & 4.176 & -4.052 & 2.611 & 36.111 & 4.601 \\
\hline Gender & 0.000 & 0.000 & 0.000 & 0.000 & 0.000 & 0.000 & 0.000 & 0.000 & 0.000 & 0.000 & 0.000 & 0.000 & 0.000 & 0.000 & 0.000 & 0.000 \\
\hline Female & 6.529 & 0.887 & 6.641 & 0.831 & -4.975 & 0.590 & -8.195 & 0.905 & 5.668 & 0.851 & 6.598 & 0.832 & -5.086 & 0.595 & -7.180 & 0.898 \\
\hline N observations & \multicolumn{8}{|c|}{12137} & \multicolumn{8}{|c|}{12137} \\
\hline
\end{tabular}


Table D4 (cont.)

\begin{tabular}{|c|c|c|c|c|c|c|c|c|c|c|c|c|c|c|c|c|}
\hline & \multicolumn{8}{|c|}{ M2 } & \multicolumn{8}{|c|}{ M3 } \\
\hline & \multicolumn{2}{|c|}{ Working class } & \multicolumn{2}{|c|}{ Intermediate } & \multicolumn{2}{|c|}{ Small employers } & \multicolumn{2}{|c|}{ Salariat } & \multicolumn{2}{|c|}{ Working class } & \multicolumn{2}{|c|}{ Intermediate } & \multicolumn{2}{|c|}{ Small employers } & \multicolumn{2}{|c|}{ Salariat } \\
\hline & AME & SE & AME & SE & AME & SE & AME & SE & AME & SE & AME & SE & AME & SE & AME & SE \\
\hline \multicolumn{17}{|l|}{ Origins-ability } \\
\hline $\begin{array}{l}\text { Consistently disadvantaged, high ability } \\
\text { Consistently disadvantaged, middle }\end{array}$ & & & & & & & & & & & & & & & & \\
\hline ability & 7.675 & 2.785 & 1.217 & 2.879 & 0.066 & 2.161 & -8.958 & 2.887 & 8.036 & 2.829 & 1.366 & 2.900 & 0.098 & 2.183 & -9.500 & 2.931 \\
\hline Consistently disadvantaged, low ability & 14.545 & 3.176 & -0.508 & 2.867 & 0.565 & 2.024 & -14.602 & 3.080 & 15.527 & 3.184 & -0.215 & 2.904 & 0.753 & 2.043 & -16.066 & 3.137 \\
\hline Intermediate, high ability & -5.216 & 2.703 & 0.695 & 2.796 & -0.092 & 2.073 & 4.614 & 2.509 & -5.866 & 2.732 & 0.205 & 2.801 & -0.361 & 2.077 & 6.022 & 2.565 \\
\hline Intermediate, middle ability & -2.532 & 2.606 & 3.609 & 2.554 & 1.144 & 1.942 & -2.220 & 2.588 & -2.429 & 2.617 & 3.556 & 2.572 & 1.088 & 1.961 & -2.214 & 2.672 \\
\hline Intermediate, low ability & 6.661 & 2.774 & 0.685 & 2.765 & 1.948 & 2.045 & -9.294 & 2.726 & 7.486 & 2.812 & 0.990 & 2.779 & 2.140 & 2.060 & -10.617 & 2.777 \\
\hline Consistently advantaged, high ability & -7.638 & 2.978 & -1.164 & 2.824 & 0.154 & 1.997 & 8.648 & 2.824 & -9.194 & 2.967 & -1.866 & 2.825 & -0.307 & 1.990 & 11.367 & 2.889 \\
\hline Consistently advantaged, middle ability & -4.150 & 2.923 & 1.243 & 2.836 & 0.640 & 2.222 & 2.267 & 3.109 & -4.727 & 2.922 & 0.861 & 2.843 & 0.391 & 2.224 & 3.474 & 3.158 \\
\hline Consistently advantaged, low ability & 1.808 & 3.451 & -0.841 & 3.471 & 2.525 & 2.507 & -3.491 & 3.606 & 1.493 & 3.428 & -0.795 & 3.494 & 2.490 & 2.524 & -3.189 & 3.672 \\
\hline \multicolumn{17}{|l|}{$\begin{array}{l}\text { Obtained further academic } \\
\text { qualifications }\end{array}$} \\
\hline Yes & -15.870 & 1.466 & -2.223 & 1.243 & -2.341 & 0.974 & 20.434 & 1.011 & & & & & & & & \\
\hline \multicolumn{17}{|l|}{$\begin{array}{l}\text { Obtained further vocational } \\
\text { qualifications }\end{array}$} \\
\hline Yes & & & & & & & & & -7.702 & 0.998 & 1.760 & 1.014 & 0.156 & 0.791 & 5.786 & 1.053 \\
\hline \multicolumn{17}{|l|}{ Initial education (ref: $5+0$-levels) } \\
\hline No qualifications & 16.915 & 1.407 & -5.326 & 1.342 & 1.618 & 0.995 & -13.208 & 1.341 & 21.089 & 1.484 & -5.652 & 1.401 & 1.817 & 0.994 & -17.254 & 1.449 \\
\hline Below O-level, NVQ 1 & 14.916 & 1.744 & -2.111 & 1.711 & 3.532 & 1.368 & -16.337 & 1.808 & 19.425 & 1.819 & -2.383 & 1.735 & 3.823 & 1.369 & -20.865 & 1.854 \\
\hline O-level passes, NVQ2 & 10.311 & 1.578 & -0.194 & 1.456 & 1.566 & 1.148 & -11.684 & 1.579 & 11.941 & 1.555 & 0.366 & 1.454 & 1.966 & 1.143 & -14.272 & 1.623 \\
\hline $2+$ A-level passes & -11.170 & 2.032 & -4.942 & 2.298 & -1.475 & 1.602 & 17.588 & 2.636 & -12.083 & 1.642 & -7.565 & 2.106 & -2.590 & 1.410 & 22.237 & 2.487 \\
\hline \multicolumn{17}{|l|}{ Tertiary sub-degree qualification, NVQ } \\
\hline 4 & -7.168 & 1.963 & -6.716 & 2.250 & 3.216 & 1.841 & 10.669 & 2.545 & -5.953 & 1.893 & -5.778 & 2.293 & 3.736 & 1.880 & 7.995 & 2.618 \\
\hline Degree, NVQ5 or 6 & -15.334 & 1.353 & -15.107 & 1.525 & -4.255 & 1.081 & 34.696 & 1.679 & -13.850 & 1.275 & -14.586 & 1.535 & -3.974 & 1.065 & 32.410 & 1.701 \\
\hline Higher degree & -17.606 & 2.617 & -17.652 & 3.750 & -5.010 & 2.313 & 40.268 & 4.128 & -15.570 & 2.703 & -16.436 & 4.093 & -4.281 & 2.498 & 36.287 & 4.446 \\
\hline \multicolumn{17}{|l|}{ Gender } \\
\hline Female & 5.969 & 0.849 & 6.663 & 0.831 & -5.037 & 0.593 & -7.595 & 0.884 & 5.067 & 0.852 & 6.769 & 0.834 & -5.056 & 0.602 & -6.780 & 0.901 \\
\hline $\mathrm{N}$ observations & \multicolumn{8}{|c|}{12137} & \multicolumn{8}{|c|}{12137} \\
\hline
\end{tabular}


Table D4 (cont.)

\begin{tabular}{|c|c|c|c|c|c|c|c|c|}
\hline & \multicolumn{8}{|c|}{ M4 } \\
\hline & \multicolumn{2}{|c|}{ Working class } & \multicolumn{2}{|c|}{ Intermediate } & \multicolumn{2}{|c|}{ Small employers } & \multicolumn{2}{|c|}{ Salariat } \\
\hline & AME & SE & AME & SE & AME & SE & AME & SE \\
\hline \multicolumn{9}{|l|}{ Origins-ability } \\
\hline \multicolumn{9}{|l|}{ Consistently disadvantaged, high ability } \\
\hline $\begin{array}{l}\text { Consistently disadvantaged, middle } \\
\text { ability }\end{array}$ & 7.436 & 2.813 & 1.314 & 2.885 & 0.073 & 2.166 & -8.823 & 2.873 \\
\hline Consistently disadvantaged, low ability & 13.970 & 3.197 & -0.278 & 2.880 & 0.622 & 2.031 & -14.322 & 3.078 \\
\hline Intermediate, high ability & -5.214 & 2.731 & 0.678 & 2.799 & -0.108 & 2.072 & 4.645 & 2.503 \\
\hline Intermediate, middle ability & -2.543 & 2.620 & 3.592 & 2.551 & 1.123 & 1.941 & -2.171 & 2.579 \\
\hline Intermediate, low ability & 6.352 & 2.976 & 0.798 & 2.768 & 1.961 & 2.049 & -9.111 & 2.721 \\
\hline Consistently advantaged, high ability & -7.838 & 2.990 & -1.096 & 2.825 & 0.163 & 1.997 & 8.772 & 2.816 \\
\hline Consistently advantaged, middle ability & -4.113 & 2.926 & 1.212 & 2.831 & 0.622 & 2.205 & 2.278 & 3.097 \\
\hline Consistently advantaged, low ability & 1.404 & 3.457 & -0.690 & 3.473 & 2.553 & 2.508 & -3.266 & 3.607 \\
\hline \multicolumn{9}{|l|}{$\begin{array}{l}\text { Obtained further academic } \\
\text { qualifications }\end{array}$} \\
\hline Yes & -14.793 & 1.459 & -2.678 & 1.235 & -2.459 & 0.967 & 19.929 & 1.014 \\
\hline \multicolumn{9}{|l|}{$\begin{array}{l}\text { Obtained further vocational } \\
\text { qualifications }\end{array}$} \\
\hline Yes & -6.112 & 0.998 & 2.501 & 1.008 & 0.597 & 0.788 & 3.013 & 1.047 \\
\hline \multicolumn{9}{|l|}{ Initial education (ref: 5+ O-levels) } \\
\hline No qualifications & 19.616 & 1.491 & -6.408 & 1.409 & 1.395 & 1.008 & -14.623 & 1.414 \\
\hline Below O-level, NVQ 1 & 17.659 & 1.795 & -3.255 & 1.739 & 3.279 & 1.367 & -17.684 & 1.844 \\
\hline O-level passes, NVQ2 & 10.889 & 1.559 & -0.372 & 1.466 & 1.585 & 1.154 & -12.103 & 1.595 \\
\hline $2+$ A-level passes & -10.821 & 1.934 & -5.179 & 2.307 & -1.569 & 1.597 & 17.569 & 2.627 \\
\hline Tertiary sub-degree qualification, NVQ 4 & -7.248 & 1.857 & -6.828 & 2.270 & 3.147 & 1.863 & 10.929 & 2.564 \\
\hline Degree, NVQ5 or 6 & -14.892 & 1.828 & -15.467 & 1.529 & -4.377 & 1.078 & 34.736 & 1.667 \\
\hline Higher degree & -16.967 & 2.424 & -18.054 & 3.767 & -5.137 & 2.283 & 40.159 & 4.081 \\
\hline \multicolumn{9}{|l|}{ Gender } \\
\hline Female & 5.476 & 0.851 & 6.879 & 0.833 & -4.978 & 0.600 & -7.377 & 0.887 \\
\hline N observations & \multicolumn{8}{|c|}{12137} \\
\hline
\end{tabular}


FIGURE D1: Estimated probability (with 95\% confidence interval) of individuals being found in the intermediate classes at age 38 by social origins and cognitive ability, for those obtaining or not obtaining further academic or vocational qualification since leaving full-time education ${ }^{(a)}$

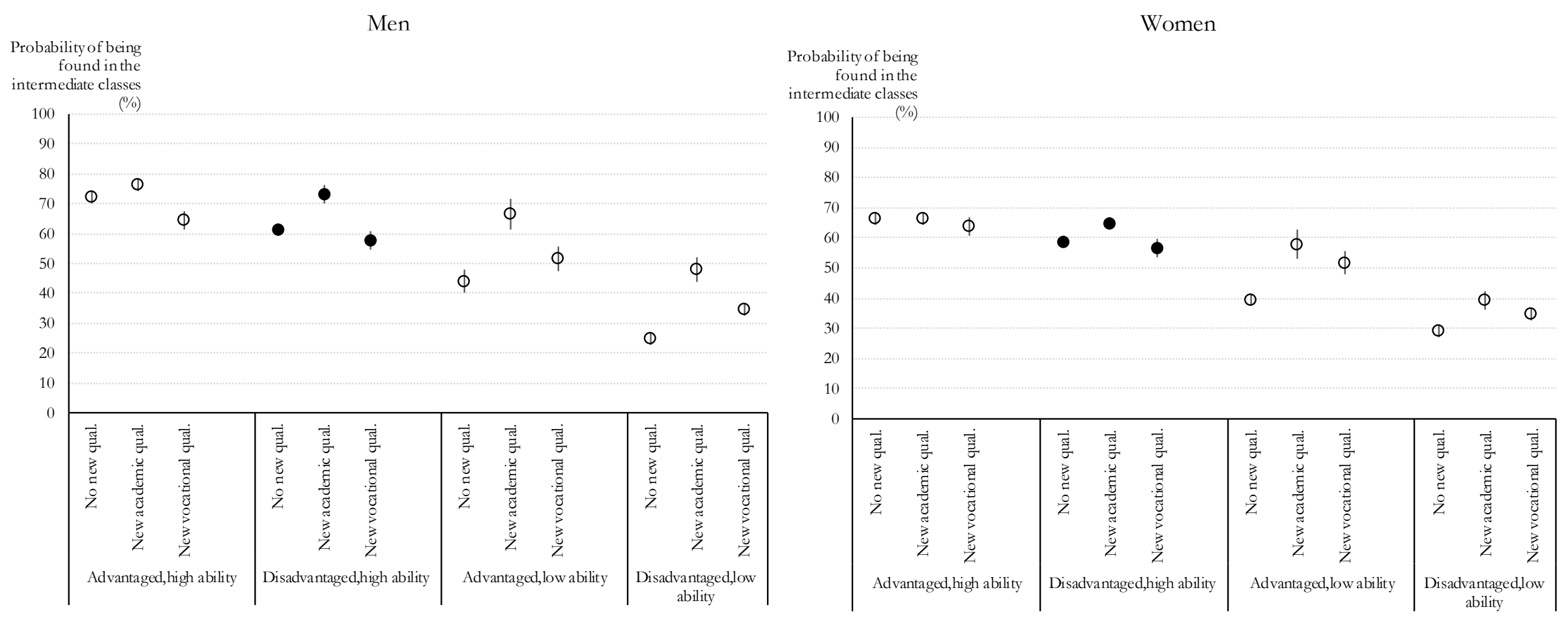

\section{Note}

(a): Based on an extension of Model 4 in Table 5 that also includes interactions between further qualifications and the origin-ability groups; model run separately by gender. 
FIGURE D2: Estimated probability (with 95\% confidence interval) of individuals being found in the class of self-employed at age 38 by social origins and cognitive ability, for those obtaining or not obtaining further academic or vocational qualification since leaving full-time education ${ }^{(a)}$

Men

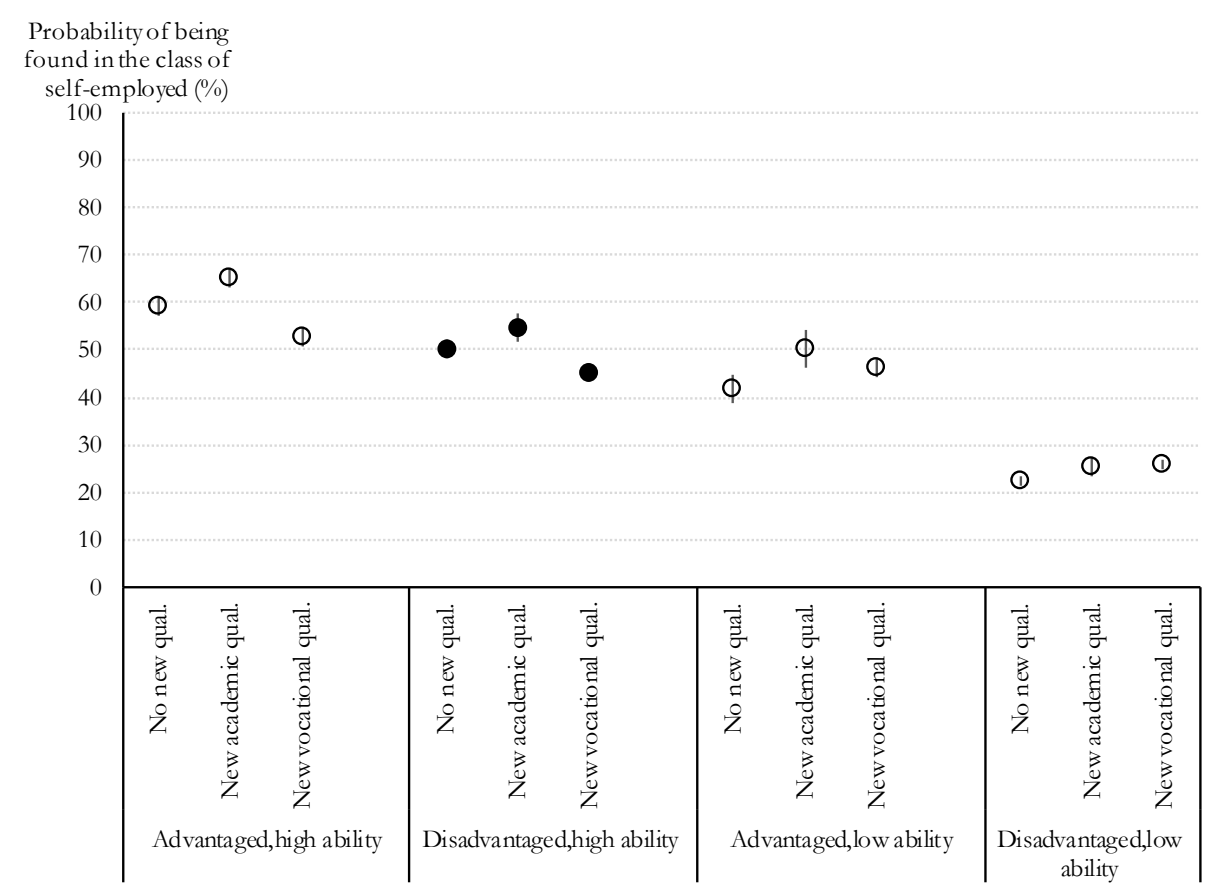

Women

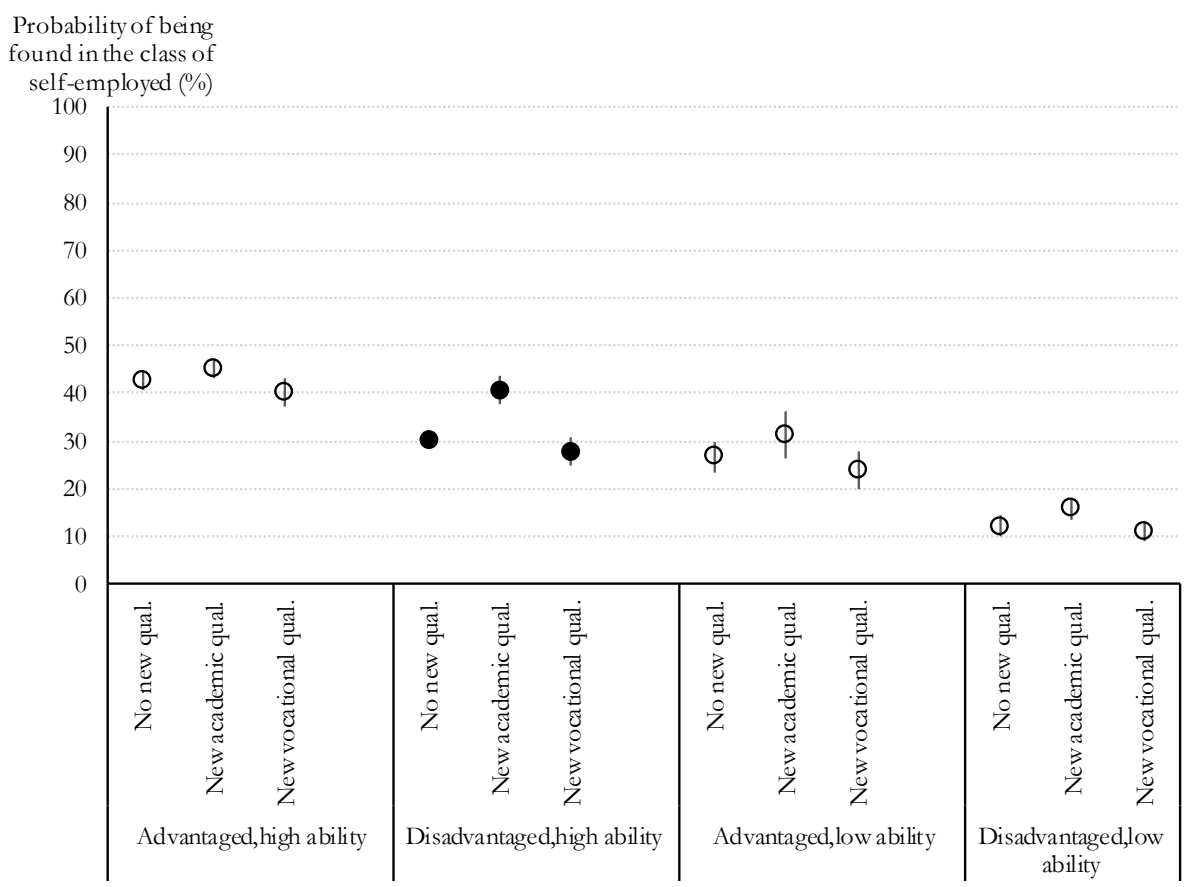

Note

(a): Based on an extension of Model 4 in Table 5 that also includes interactions between further qualifications and the origin-ability groups; model run separately by gender. 


\section{References}

Allison, P. D. (2001) Missing data. Thousand Oaks, CA: Sage.

Cattell, R. B. (1971). Abilities: Their Structure, Growth and Action. Boston, MA: Houghton Mifflin.

Chan, T.-W. and Goldthorpe, J. H. (2004) 'Is There a Status Order in Contemporary British Society? Evidence from the Occupational Structure of Close Friendship', European Sociological Review, 20: 383-401.

Deary, I. J. (2001). Intelligence: A Very Short Introduction. Oxford: Oxford University Press.

Erikson, R. (1984) 'Social Class of Men, Women and Families', Sociology, 18: 500-514.

Jensen, A. R. (1998). The g Factor: The Science of Mental Ability. Westport, CT: Praeger.

Kuha, J. (2013). Trends in Intergenerational Class Mobility in Britain: New Findings From the Analysis of Birth Cohort Data. A Note on the Multiple Imputation of Missing Data. Oxford: University of Oxford.

Marks, G. N. (2014). Education, Social Background and Cognitive Ability: The Decline of the Social. London:

Routledge.

Office for National Statistics (ONS) (2005) The National Statistics Socio-economic Classification User Manual. London: Office for National Statistics.

Schoon, I. (2008). A Transgenerational Model of Status Attainment: The Potential Mediating Role of School Motivation and Education, National Institute Economic Review, 205, 72-82.

Schoon, I. (2010). Childhood Cognitive Ability and Adult Academic Attainment: Evidence from Three British Cohort Studies, Longitudinal and Life Course Studies, 1, 241-258.

Spearman, C. (1904). "General Intelligence", Objectively Determined and Measured, American Journal of

Psychology, 15, 201-293.

von Hippel, P. \& Lynch, J. (2013). Efficiency Gains from Using Auxiliary Variables in Imputation. Cornell University Library. 